ARTICLE

https://doi.org/10.1038/s41467-021-27861-w

\title{
Multifactorial engineering of biomimetic membranes for batteries with multiple high-performance parameters
}

Mingqiang Wang (1,2,3,6, Ahmet E. Emre 2,3,4,5,6, Ji-Young Kim (1) 2,3,4, Yiting Huang ${ }^{1}$, Li Liu', Volkan Cecen²,3, Yudong Huang ${ }^{1} \&$ Nicholas A. Kotov (10) 2,3,4,5凶

Lithium-sulfur (Li-S) batteries have a high specific capacity, but lithium polysulfide (LPS) diffusion and lithium dendrite growth drastically reduce their cycle life. High discharge rates also necessitate their resilience to high temperature. Here we show that biomimetic selfassembled membranes from aramid nanofibers (ANFs) address these challenges. Replicating the fibrous structure of cartilage, multifactorial engineering of ion-selective mechanical, and thermal properties becomes possible. LPS adsorption on ANF surface creates a layer of negative charge on nanoscale pores blocking LPS transport. The batteries using cartilagelike bioinspired ANF membranes exhibited a close-to-theoretical-maximum capacity of 1268 $\mathrm{mAh} \mathrm{g}^{-1}$, up to $3500+$ cycle life, and up to $3 \mathrm{C}$ discharge rates. Essential for safety, the high thermal resilience of ANFs enables operation at temperatures up to $80^{\circ} \mathrm{C}$. The simplicity of synthesis and recyclability of ANFs open the door for engineering high-performance materials for numerous energy technologies.

\footnotetext{
${ }^{1}$ School of Chemistry and Chemical Engineering, Harbin Institute of Technology, Harbin 150001, People's Republic of China. ${ }^{2}$ Department of Chemical Engineering, University of Michigan, Ann Arbor, MI 48109, USA. ${ }^{3}$ Biointerfaces Institute, University of Michigan, Ann Arbor, MI 48109, USA. ${ }^{4}$ Department of Materials Science and Engineering, University of Michigan, Ann Arbor, MI 48109, USA. ${ }^{5}$ Department of Biomedical Engineering, University of Michigan, Ann Arbor, MI 48109, USA. ${ }^{6}$ These authors contributed equally: Mingqiang Wang, Ahmet E. Emre. ${ }^{\varpi_{e}}$ email: kotov@umich.edu
} 
T he high theoretical specific capacity of $1675 \mathrm{mAh} \mathrm{g}^{-1}$, environmental friendliness, and earth-abundance of elements forming lithium-sulfur (Li-S) batteries make them an attractive platform for energy storage in a variety of technological fields from electric vehicles to robotics and from power grids to aerospace engineering ${ }^{1}$. However, the diffusion of lithium polysulfides (LPS, $\left.\mathrm{Li}_{2} \mathrm{~S}_{X}, 4 \leq x \leq 8\right)^{2}$ from cathode to anode drastically reduces their cycle life, overall capacity, and Coulombic efficiency ${ }^{3,4}$. Additionally, LPS layers passivate both the electrodes, leading to a significant increase in impedance and thus to energy losses ${ }^{5}$. The non-uniform surface layer on the anode also promotes the growth of dendrites, which represents another serious issue for Li-S batteries that causes similar issues compounded by short-circuiting and overheating.

The extensive research effort in the past was invested into designing materials for sulfur cathode that would minimize LPS release. It was shown that immobilization of LPS is possible by encapsulating sulfur into microporous carriers made from nanocarbons $s^{6,7}$, conductive polymers ${ }^{8,9}$, transition metal oxides ${ }^{1}$, and metal-organic frameworks ${ }^{10,11}$. Indeed, nanoporous barriers in the cathode improved the retention of sulfur within the cathode. However, there is still considerable room for improvement in the cycle life and overall performance of Li-S batteries addressing the structural complexity of cathode material and improving electron transport through electrode material ${ }^{12,13}$.

The problem of the LPS diffusion can also be approached by optimizing the materials design of ion-conducting membranes that can block the LPS transport from S cathode to $\mathrm{Li}$ anode. Simultaneously, these membranes must allow the facile transport of $\mathrm{Li}^{+}$ions ${ }^{5,14}$. Significant advances in this area were achieved using coatings from carbonaceous materials ${ }^{15-17}$, polymers $^{18}$, metal foams ${ }^{9-21}$ metal-oxide layers ${ }^{22,23}$, and metal oxides with carbon $^{24,25}$. The great challenge for all of these materials solutions for LPS membranes is to combine at least two contrarian materials properties-efficient ion transport and mechanical robustness in one material or a coating ${ }^{5,15,26}$. Among the latter, polymers with high shear modulus are necessary to suppress dendrite growth on lithium anodes ${ }^{27}$ while high mechanical strength ( $>98 \mathrm{MPa}$ ) and thermal stability (1 h @ 90C with $<5 \%$ shrinkage) are essential for the longevity of the batteries in realworld conditions ${ }^{28}$, for instance, in electric vehicles. The prior experimental and computational data show this materials engineering task is difficult $5,15,26,29,18$ and requires a new approach in materials design.

Here, we show that the ion-selective membranes engineered using sequential deposition of nanofibers enable nearly complete prevention of the LPS diffusion from cathode to anode. The structural design for this membrane was informed by the prior studies of ion channels in cell membranes known for efficient ion transport combined with high ion selectivity ${ }^{30}$, as well as cartilage known for unique mechanical properties ${ }^{22}$. The design of cartilage and several other biological tissues is based on highly interconnected nanofiber networks engendering their unique mechanical, adhesive, and transport properties ${ }^{23,31}$. Their topology reflected indistinct interconnectivity, and percolation enables effective stress transfer providing the toughness and flexibility, which can be replicated in composites made from aramid nanofibers (ANFs). ANFs are the nanoscale version of Kevlar fibers $^{32}$, and multifunctional ANF-based composites have been fabricated inspired by cartilage ${ }^{33}$. The direct analogy between the organization of nanofibers in ANF membranes and cartilage was recently demonstrated by evaluating their connectivity using Graph Theory ${ }^{34}$. ANF-based composites can also be engineered into stratified membranes with nanoscale porosity $(n p-A N F)$ and charge sieving capabilities due to the spontaneous adsorption of LPS layer on $n p$-ANF surface. Numerical simulations confirm that negatively charged single-nanometer pores of $n p$-ANF strongly inhibit LPS shuttling while affording rapid transport of $\mathrm{Li}^{+}$ions.

ANF-based composites have been utilized as electrode materials $s^{35,36}$ and separators ${ }^{37-39}$ in various energy storage systems ${ }^{40,41}$ including lithium sulfur batteries ${ }^{42}$ due to their high mechanical and thermal properties, similarly, $n p-A N F$ membranes also display a high Young's modulus of $E=9.2 \pm 0.5 \mathrm{GPa}$ (55 times higher than Celgard ${ }^{T M} 2400$ ) and high thermal resistance $\left(600^{\circ} \mathrm{C}\right)$. These properties make possible simultaneous suppression of lithium dendrites extending the life cycle of the $\mathrm{Li}-\mathrm{S}$ batteries to $3500+$ cycles at 3C. The combination of properties found in $n p-A N F$ resulted in high efficiency of LPS blocking and remarkable stability over long-term cycling, even for hightemperature environments.

\section{Results}

Characterization of the $n p-A N F$ membrane. A method of spinassisted layering assembly ${ }^{43}$ with a positively charged poly(diallyldimethylammonium) partner polymer (PDDA) facilitating adhesion of the subsequent spin-layers is conceptually similar layer-by-layer (LBL) deposition ${ }^{44,45}$ was used to fabricate membranes from ANF dispersions (see "Methods"). Using this technique, the thickness of membrane can be easily varied by increasing or decreasing the number of deposition cycles (Supplementary Fig. 1), which is required for the optimization of flux and selectivity of the ion-transporting membranes. By repeating the spin deposition cycle three times, we obtained ANF composite membranes with a smooth surface (Fig. 1B, C and Supplementary Fig. 1) and a thickness of $5.8 \pm 0.50 \mu \mathrm{m}$ (Supplementary Fig. 1D), which is much about four times thinner than that of Celgard ${ }^{T M}$ 2400 membranes with a typical thickness of $25 \mu \mathrm{m}$. Reducing the membrane thickness represents a critical technological target because it enables increasing the thickness of active materials on both cathode and anode, increasing the overall battery capacity. The thickness of the state-of-the-art ion-conducting membranes for Li-S batteries is between 20 and $30 \mu \mathrm{m}$. (Supplementary Tables 5-8). Thermogravimetric analysis (TGA) on $n p-A N F$ membrane indicates that no significant weight loss occurs below $600^{\circ} \mathrm{C}$ in $\mathrm{N}_{2}$ atmosphere (Fig. 1D), and the differential scanning calorimetry (DSC) analysis on $n p-A N F$ confirms no significant change occurring with $n p-A N F$ until $500^{\circ} \mathrm{C}$ (Supplementary Figs. 2, 3). np-ANF membranes also show lower electrolyte contact angle and higher electrolyte uptake compared to Celgard ${ }^{T M}$ 2400 , which reduces internal resistance needed to achieve superior rate charge-discharge rate (Supplementary Fig. 4). The highly interconnected cartilage-like pectolated network of nanofibers also engenders small volume changes of $n p-A N F$ after being fully wetted by electrolyte, which facilitates tight adhesion to electrodes and is needed for efficient dendrite suppression that may not be the case for many other membrane architectures (Supplementary Fig. 5). np-ANF membranes obtained by spincoating with PDDA also features nanoscale pores $0.9-1.2 \mathrm{~nm}$ in diameter as determined by the Barrett-Joyner-Halenda (BJH) analysis (Supplementary Fig. 6), which is smaller than the hydrodynamic diameter of $\mathrm{L}_{2} \mathrm{~S}_{4}$ of $1.3-1.5 \mathrm{~nm}^{2,46,47}$. These pores are at least one order of magnitude smaller than those found in Celgard $^{T M} 2400$ where the BJH pore size exceeds $25 \mathrm{~nm}$ (Supplementary Fig. 7).

Synergistic effects of negative charge and narrow pore size of $\boldsymbol{n} \boldsymbol{p}$ - $\boldsymbol{A N F}$. The pore diameter in the range of single nanometers has two essential benefits for battery membranes related to dendrite suppression and ion transport ${ }^{46}$. First, lithium dendrites have a diameter of around $300 \mathrm{~nm}$ in growth point (Fig. 1E, F). Providing sufficient mechanical properties ${ }^{27,48}$, membranes with a 

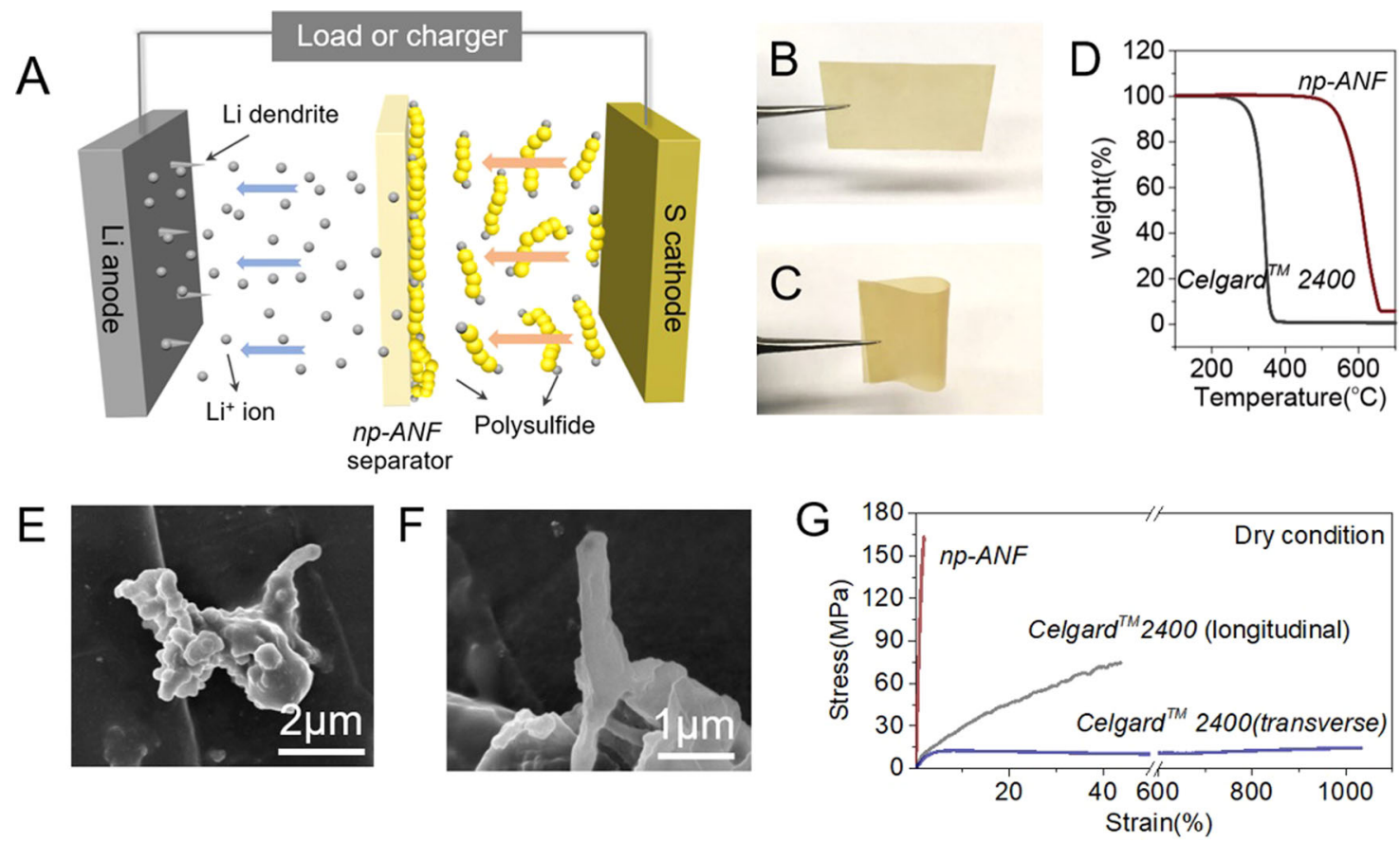

Fig. 1 Characterization of the $\boldsymbol{n p}$-ANF membrane. A Schematic configuration of a Li-S cell with a $n p-A N F$ membrane between the sulfur cathode and the lithium anode. B, C Photographs of an np-ANF membrane. D Thermogravimetric analysis curves for $n p-A N F$ membrane and Celgard ${ }^{T M} 2400$. E, F SEM images of the tip of lithium dendrite. G Stress-strain curves for $n p-A N F$ and Celgard ${ }^{T M} 2400$.

single nanometer pore size can suppress the growth dendrites more efficiently than those with wider channels. Notably, the Young's modulus of $n p-A N F$-based membranes no matter in dry $(E=9.2 \pm 0.5 \mathrm{GPa})$ or electrolyte wet state $(E=8.1 \pm 0.4 \mathrm{GPa})$ are higher than most of previously reported membranes (Supplementary Figs. 8, 9 and Supplementary Table 2). Compared with Celgard 2400 in longitudinal directions with $E=0.17 \pm 0.02 \mathrm{GPa}$ in dry state and $E=0.15 \pm 0.02 \mathrm{GPa}$ in electrolyte wet state, it corresponds to $c a 55 \mathrm{x}$ improvement in the Young's modulus (Fig.1G, Supplementary Fig. 10, and Supplementary Table 1). Even after a long electrochemical looping process, $n p-A N F$ can still maintain its initial Young's modulus, while CelgardTM 2400 reduced significantly and became unstable, which may be caused by dendrite growth on the membrane surface (Supplementary Fig. 10 and Supplementary Table 1). The nano-indentation test further confirms it due to the higher depth of Celgard ${ }^{T M} 2400$ membrane compared to the $n p$-ANF when the same pressure is applied (Supplementary Fig. 11).

Most importantly, at a high-temperature environment of $80^{\circ} \mathrm{C}$, $n p-A N F$ still processes a high Young's modulus of $3.7 \mathrm{GPa}$, which is much better than the other similar types of separators (Supplementary Fig. 10 and Supplementary Table 1), ensuring the stability of the batteries during charge-discharge operations. The tensile strength and Young's modulus of Celgard ${ }^{T M} 2400$ whether measured in the transverse or longitudinal direction, drop markedly as temperature increase reducing by $70 \%$ for Young's modulus with $0.05 \pm 0.003 \mathrm{GPa}$ in a longitudinal direction and $0.4^{*} 10^{-3} \pm 0.02 * 10^{-3} \mathrm{GPa}$ in transverse direction at $80^{\circ} \mathrm{C}$. Obviously, it is difficult for Celgard ${ }^{T M} 2400$ separator to maintain its original mechanical performance in a hightemperature environment and ensuring the stable operation of the Li-S batteries.

The design criteria regarding Young's modulus that is easier to measure than many other mechanical characteristics can be derived using the mathematical derivation relating the shear modulus, $G_{\text {polymer }}$, of the polymeric electrolyte and its Young's modulus, $E_{\text {polymer }}$, following the standard Monroe and Newman model ${ }^{27}$. Derivations included in Supplementary Information show that the original expression for the mechanical properties of ion-conducting membranes $G_{\text {polymer }} / G_{\mathrm{Li}}=1.65$ can be converted into $E_{\text {polymer }} / E_{\mathrm{Li}}=1.53$ (Supplementary Information). The advantage of the dendrite suppression relationship based on Young's moduli is that it is more practical because the values of Young's moduli are easier to measure and are available for larger number of composite and other materials. Note that this conversion does not make any additional assumptions besides those in the Monroe and Newman model or currently used in the field (Supplementary Information).

Secondly, the negative surface potential of $n p-A N F^{39,40,49}$ and the small diameter of the pores make the double electric layers extending from the pore walls overlap incompletely compensating the surface charge ${ }^{50,51}$. Being immersed in electrolytes typical for lithium batteries, such membranes are to reject negatively charged chains of LPS due to the repulsion from the channel walls. The nanoscale confinement enables, therefore, a high degree of selectivity for the transport of ions through them recreating the functional analogs of ion channels known from biology ${ }^{52,53}$

An additional source of charge on the nanofibers can be the adsorption of chemical species from the electrolyte. We found that LPS can spontaneously bind to $n p-A N F$ creating the layer of strongly bound negative charge on them, which rejects transport of LPS but facilitates the transportation of lithium ions. $n p-A N F$ membrane was immersed into $0.5 \mathrm{M} \mathrm{Li}_{2} \mathrm{~S}_{4}$ in DOL/DME for $10 \mathrm{~h}$ at room temperature $\left(25^{\circ} \mathrm{C}\right)$. After repeated five times wash in copious amount of DOL/DME solvent, a large amount of sulfur was still detected on the surface of the membrane by the XPS analysis (Fig. 2A and Supplementary Figs. 14, 15), indicating the strong adsorption of polysulfides on $n p-A N F$. This LPS adsorption on the $n p$-ANF membranes was confirmed by EDAX and the Raman scattering (Fig. 2B, C). The two characteristic Raman scattering peaks of LPS observed in freely dissolved states at 450 and $520 \mathrm{~cm}^{-1}$ are broadened and appear at 400 and $440 \mathrm{~cm}^{-1}$ when adsorbed on $n p-A N F$. Broadening is expected for adsorbed 

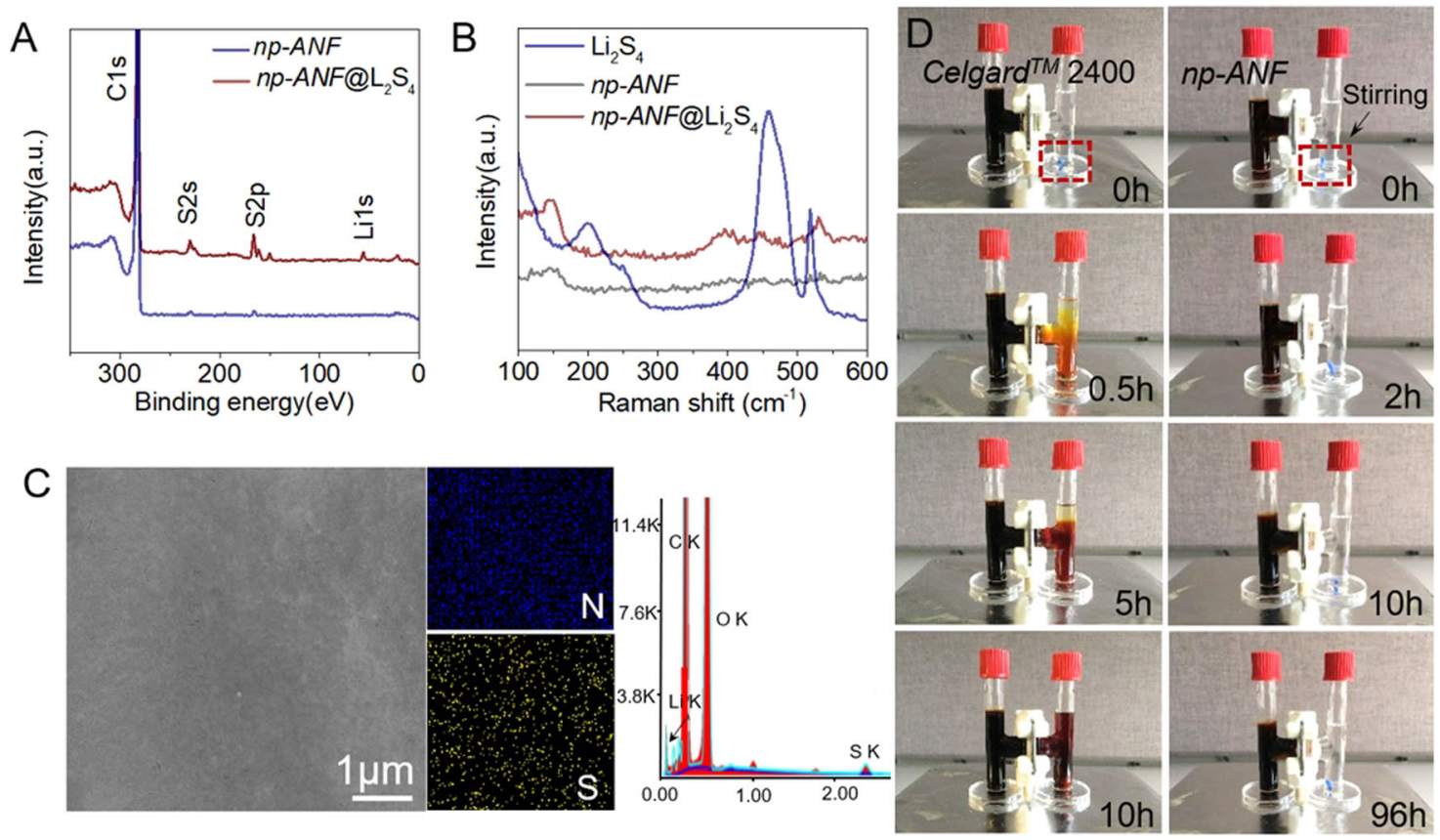

Fig. 2 Polysulfide-blocking capability of the $\boldsymbol{n p}$-ANF separator. XPS survey (A); Raman scattering spectra (B); SEM image, EDAX spectra, and the corresponding $\mathrm{N}$ and $\mathrm{S}$ element mapping images (C) for the $n p-A N F$ before and after adsorption test $\mathrm{Li}_{2} \mathrm{~S}_{4}$ solution followed by rinsing with $\mathrm{DOL} / \mathrm{DME}$ solution and drying in a glovebox. D Diffusion of LPS in H-type cell through Celgard ${ }^{T M} 2400$ and $n p$-ANF membrane.

LPS due to multiplicity of the conformational states of LPS on $n p$ ANF composite.

$n p-A N F$ composites with negative charges on cylindrical pores 39,49 are expected to be permeable for lithium ions but reject LPS (Fig. 2D) ${ }^{54}$ due to their negative charge, large size, and cooperative binding to the channel walls. Permeation behavior of LPS through the $n p-A N F$ membrane was investigated in an $\mathrm{H}$-cell (Fig. 2D) filled with 1,3-dioxolane (DOL) and dimethoxyethane (DME) in $1 / 1 \mathrm{v} / \mathrm{v}$ ratio that is commonly used in the $\mathrm{Li}-\mathrm{S}$ batteries ${ }^{55}$. DOL/DME solvent without LPS was placed in the right chamber while solvent with $0.5 \mathrm{M} \mathrm{Li}_{2} \mathrm{~S}_{4}$ was in the left chamber. Driven by the concentration gradient, LPS easily diffused across the Celgard ${ }^{T M} 2400$ and the right chamber turned from colorless to dark brown within $10 \mathrm{~h}$. In contrast, the diffusion of LPS was blocked by $n p-A N F$ membrane (Fig. 2D) and the right chamber stayed colorless after $96 \mathrm{~h}$ even under a strong stirring.

We further investigated LPS blocking mechanism with numerical simulation of ion transport by finite element computations. The structure of the nanochannel of ANF separator was modeled as a single $10 \mathrm{~nm}$ long channel with $1 \mathrm{~nm}$ diameter connecting two reservoirs (inset, Fig. 3A). The diameter of the model channel has been determined by experimental pore size measured by the $\mathrm{BJH}$ analysis (Supplementary Fig. 6) and is similar to the diameter of pores in proteinbased ion-channels in the cell membranes. Note that the actual channel is longer than $10 \mathrm{~nm}$ and the pore structure is more complex, which represents that our model can even underestimate the selectivity of the transport. Both the reservoirs and nanochannel are represented by dielectric blocks with the electrolyte. The limitation caused by the size of reservoirs of model is compensated by inflow boundary setting of anion and cation (Fig. 3B). The anode and cathode with potential difference of $2 \mathrm{~V}$ had been set at the two ends of reservoirs for common electrostatic boundary condition of the models while surface charged density of $-8 \mathrm{mC} / \mathrm{m}^{2}$ has been selectively applied to the boundary of $n p-A N F$ separator for comparison. At initial, reservoir on cathode side (reservoir 1, Fig. 3B) is only filled with LPS anions (concentration of LPS-, $c_{\mathrm{LPS}}=1 \mathrm{M}$ ), whereas the whole system including nanochannel is uniformly filled with lithium cation (concentration of $\mathrm{Li}+, c_{\mathrm{Li}+}=1 \mathrm{M}$ ). Two different electrostatic conditions, with and without surface charge density on the surface of $n p-A N F$ membrane, were applied to the model and time-dependent studies were performed by solving the coupled Poisson, Nernst-Planck, and Navier-Stokes equations (Supplementary Information). As expected, both LPS anion and Li cation can freely pass through the nanochannel that does not have a surface charge (Fig. 3C, D, I and Supplementary Movies 1,2). When the model includes, however, the negative surface charge on the channel walls, the transport of LPS including some of the smallest LPS species, such as including $\mathrm{Li}_{2} \mathrm{~S}_{4}$, is blocked (Fig. 3D, ii and Supplementary Movie 4). $\mathrm{Li}^{+}$ cations still pass though unimpeded (Fig. 3C, ii and Supplementary Movie 3). Note that until $200 \mathrm{~ns}$, some adsorption of $\mathrm{Li}$ cation layer on the wall of $n p$-ANF has been observed although it does not block the passage of ion transport. Ion transportation simulation model through large pores $(>20 \mathrm{~nm}$ has also been modeled) to evaluate the performance of Celgard ${ }^{\mathrm{TM}}$ for LPS leakage (Supplementary Fig. 12). Thus, the computational model demonstrates that $n p$-ANF can selectively block LPS transport solely due to electrostatic repulsion, even excluding the size selectivity effect, which simplifies the engineering of the membranes for a variety of technologies.

Ion-selective $n p$ - $A N F$ membranes enable $\mathrm{Li}-\mathrm{S}$ batteries with high sulfur loading. In the cyclic voltammograms $(\mathrm{CV})$ of Li-S battery cell with $n p$-ANF membranes, two distinctive reduction peaks and a strong oxidation peak appear at 2.36, 2.02, and $2.31 \mathrm{~V}$, respectively (Fig. $4 \mathrm{~A}$ ). For simplicity of notations, the anodic peak and the two cathodic peaks will be denoted here as peaks $\alpha, \beta$, and $\gamma$, respectively. The peak $\gamma$ at $2.36 \mathrm{~V}$ is attributed to the reduction of $\mathrm{S}_{8}$ to intermediate LPS $\left(\mathrm{Li}_{2} \mathrm{~S} x, 4 \leq x \leq 8\right)$, while the second reduction peak $\beta$ at $2.02 \mathrm{~V}$ is ascribed to the further reduction of intermediate LPS to insoluble $\mathrm{Li}_{2} \mathrm{~S}$ and $\mathrm{Li}_{2} \mathrm{~S}_{2}$. The 
A

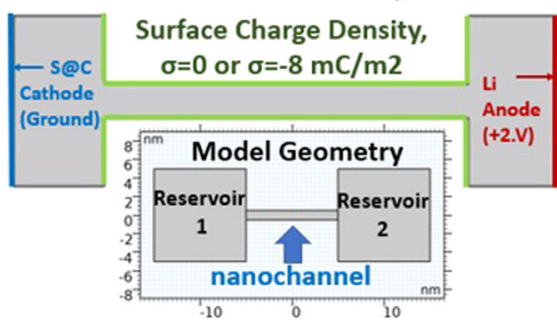

C $\mathrm{C}_{\mathrm{Li}+}$ $\left(\mathrm{mol} / \mathrm{m}^{3}\right)$

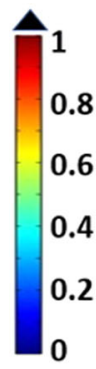

D

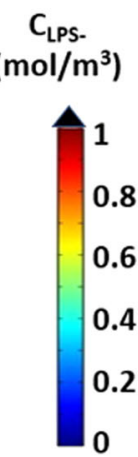

(i)

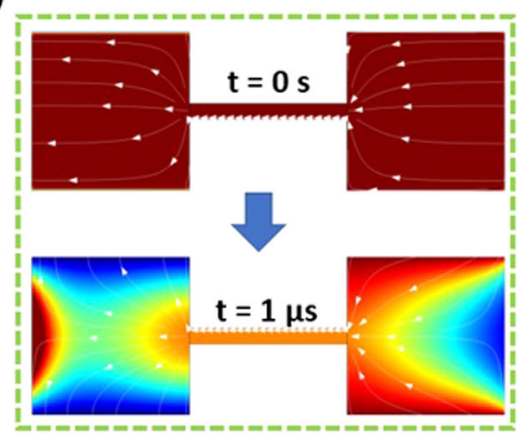

(i)

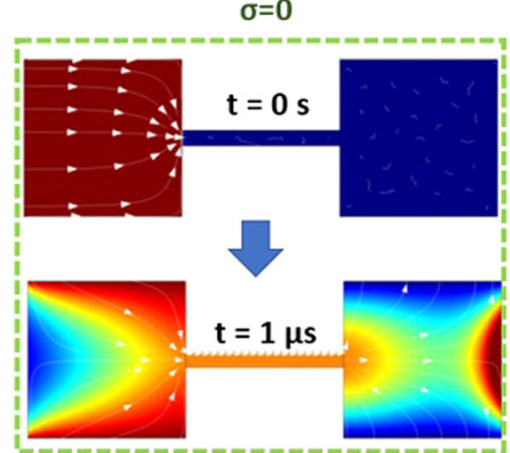

B Boundary Condition for Ion Species Transport $\mathrm{Li}+\left(\mathrm{C}_{\mathrm{Li}+}=1 \mathrm{~mol} / \mathrm{m}^{3}\right)$

LPS- $\left(C_{\text {LPS }}=1 \mathrm{~mol} / \mathrm{m}^{3}\right)$

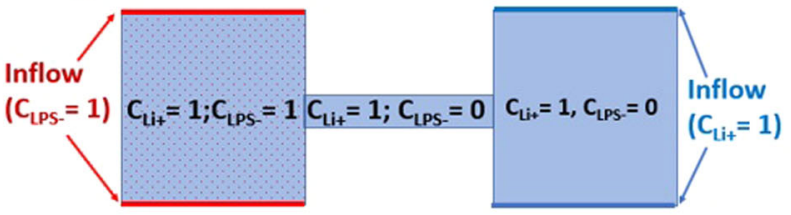

(ii)

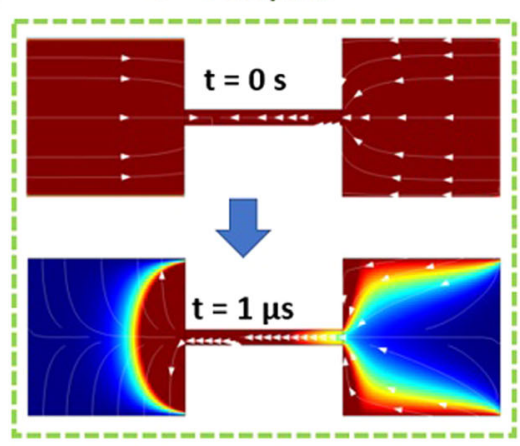

(ii)

$\sigma=-8 \mathrm{mC} / \mathrm{m} 2$

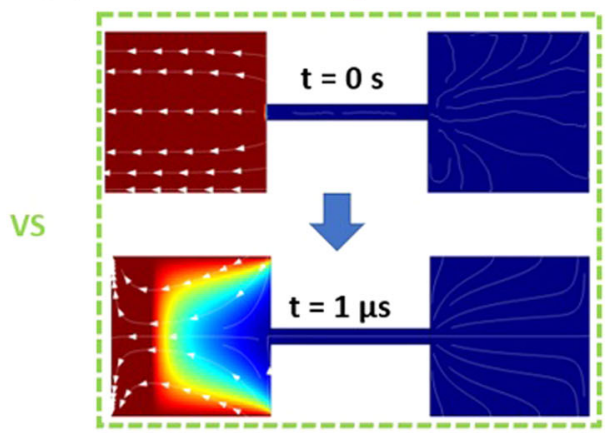

Fig. 3 Computational analysis on transport of charged ion species through a single nanochannel. A Electrostatic boundary condition including potential set for cathode (ground at S@C, conventional sulfur in carbon) and anode ( $2 \mathrm{~V}$ at Li, Lithium metal), and surface charged density ( $\sigma$ ) on ANF wall. B Boundary condition for ion transport module for LPS anion and Li cation. The concentration map and streamline change (from $t=0$ to $t=1 \mu \mathrm{s}$ ) of Li cation (C) and LPS anion (D) with (i) and without (ii) surface charge density on boundary of np-ANF separator.

strong oxidation peak a centered at $2.31 \mathrm{~V}$ corresponds to the delithiation of $\mathrm{Li}_{2} \mathrm{~S}_{2} \mathrm{Li}_{2} \mathrm{~S}_{2}$ into $\mathrm{Li}_{2} \mathrm{~S} x(4 \leq x \leq 8)$ and eventually to $\mathrm{S}_{8}{ }^{5}$. In the subsequent cycles, the intensities of reduction and oxidation peaks remain almost unchanged.

Using the classical Randles-Sevick equation ${ }^{3,56}$, one can understand further $\mathrm{Li}^{+}$ion diffusion properties, acquiring $\mathrm{CV}$ curves under different scanning rates ranging from 0.1 to $0.5 \mathrm{mV} \mathrm{s}^{-1}$. The diffusion coefficients were determined to be $D_{\mathrm{Li}+}\left(\alpha_{1}\right)=9.263 \cdot 10^{-8} \mathrm{~cm}^{2} \mathrm{~s}^{-1}, D_{\mathrm{Li}+}\left(\beta_{1}\right)=5.310 \cdot 10^{-8} \mathrm{~cm}^{2} \mathrm{~s}^{-1}$, and $D_{\mathrm{Li}+}\left(\gamma_{1}\right)=0.421 \cdot 10^{-8} \mathrm{~cm}^{2} \mathrm{~s}^{-1}$ for $n p-A N F$, which almost equal to the diffusion coefficients for the Celgard ${ }^{T M} 2400$ of $D_{\mathrm{Li}+}\left(\alpha_{2}\right)=9.693 \cdot 10^{-8} \mathrm{~cm}^{2} \mathrm{~s}^{-1}, D_{\mathrm{Li}+}\left(\beta_{2}\right)=5.192 \cdot 10^{-8} \mathrm{~cm}^{2} \mathrm{~s}^{-1}$, and $D_{\mathrm{Li}+}\left(\gamma_{2}\right)=0.567 \cdot 10^{-8} \mathrm{~cm}^{2} \mathrm{~s}^{-1}$, respectively (Supplementary Fig. 15 and Supplementary Table 3 ). The lithium-ion transference number $\left(t_{\mathrm{Li}+}\right)$ of $n p-A N F$ separator (0.63) is almost similar to that pure Celgard 2400 (0.68) (Supplementary Fig. 16 and Supplementary Table 3). These data indicate that $n p$ $A N F$ does not affect the diffusion properties of $\mathrm{Li}^{+}$. Linear sweep voltammetry (LSV) indicates the high electrochemical stability of $n p-A N F$ in Li-S batteries (Supplementary Fig. 17), suggesting that $n p-A N F$ separator are suitable for Li-S batteries.
Diffusion of LPS through membranes is detrimental effects for Coulombic efficiency of Li-S batteries even for low charge/ discharge rate of 0.1C. Coulombic efficiency is less than $70-90 \%$ for common Li-S batteries. Coulombic efficiency of the cells being cycled at $0.1 \mathrm{C}$ for 300 cycles as 98 and $75 \%$ after for $n p$ - ANF and Celgard ${ }^{T M}$ 2400, respectively (Fig. 4B). Besides Coulombic efficiency, the discharge capacity also increased accordingly because the $n p-A N F$ membranes hindered the chemical reactions between metallic lithium and high-order LPS, reducing the loss of active material loss. For example, the initial discharge capacity of $1268 \mathrm{mAh} \mathrm{g}^{-1}$ obtained on the cell with an $n p-A N F$ was higher than that for Celgard ${ }^{T M} 2400$ with $1029 \mathrm{mAh} \mathrm{g}^{-1}$ (Fig. 4C). Furthermore, the capacity decay rate was also reduced from $0.20 \%$ of Celgard ${ }^{T M} 2400$ membrane to $0.092 \%$ per cycle. Comparing to other membranes designed for Li-S batteries, $n p-A N F$ membranes have an advantage because they improve the cycle life for long term at different charge/discharge rate (Supplementary Table 5). When needed, the cycle life, as well as the Coulombic efficiency, could be further enhanced by increasing the thickness of $n p-A N F$. However, it will increase the diffusion path length and internal resistance (Supplementary Fig. 18) ) $^{57,58}$ with concomitant reduction of 

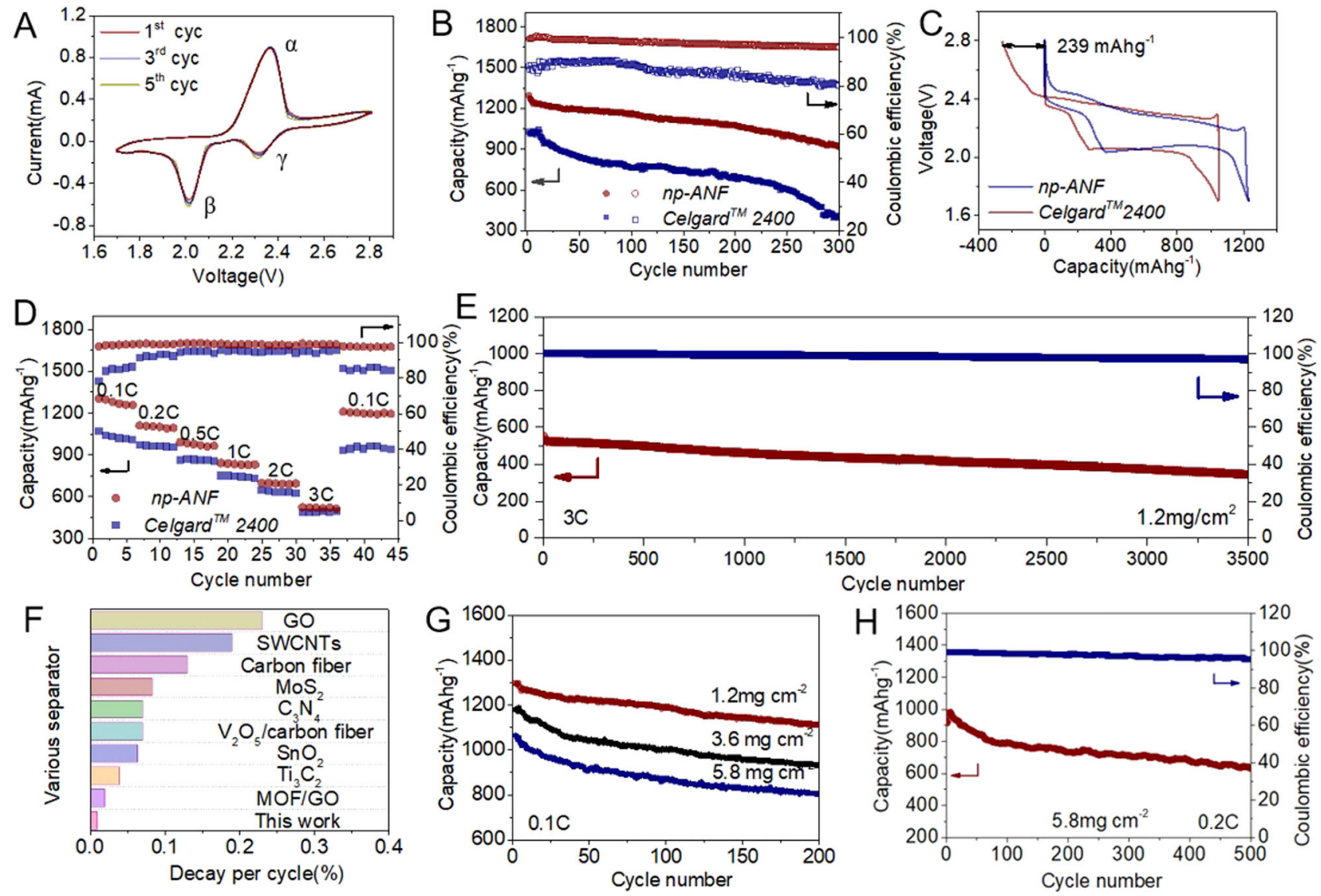

Fig. 4 Electrochemical performance of the Li-S batteries with $\boldsymbol{n p}$-ANF and Celgard ${ }^{\mathbf{T M}} \mathbf{2 4 0 0}$ membrane. A CV profiles with np-ANF at a scan rate of $0.1 \mathrm{mV} \mathrm{s}^{-1}$; B Cycling performance comparison of Li-S batteries with $n p-A N F$ and Celgard ${ }^{T M} 2400$ membrane at a rate of $0.1 C$; C Galvanostatic charge-discharge profiles of $n p-A N F$ and Celgard ${ }^{T M} 2400$ membrane at a rate of 0.1C; D Rate performance of Li-S batteries ranged 0.1C to 3C with $n p-A N F$ and its comparison of Celgard ${ }^{T M}$ 2400; $\mathbf{E}$ Cycling performance Li-S batteries with np-ANF membrane at a rate of $3 \mathrm{C}$ over a period of 3500 cycles. $\mathbf{F}$ The decay per cycle of Li-S batteries with various membrane Table S5); G Cycling performance of Li-S batteries at $0.1 \mathrm{C}$ at various sulfur loading. $\mathbf{H}$ Cycling performance Li-S batteries with $n p-A N F$ membrane at a rate of $0.2 \mathrm{C}$ after 500 cycles at sulfur loading of $5.8 \mathrm{mg} \mathrm{cm}^{-2}$.

capacity. One can expect that various energy consumption patterns will impose different preferences to Li-S battery operations. The ability of $n p-A N F$ to address different requirements will be essential for the future multiparameter performance optimization of charge storage devices.

Electrochemical impedance spectroscopy (EIS) of the Li-S cells were interpreted using equivalent circuits in Supplementary Fig. 19. Batteries with $n p-A N F$ membranes showed a more considerable resistance compared to Celgard ${ }^{T M} 2400$ before cycling (Supplementary Fig. 19A), which is expected considering the reduced pore size in these ion-conductive membranes. However, after 100 cycles (Supplementary Fig. 19B), the $R_{\mathrm{ct}}$ value of the cell with $n p$-ANF significantly decreases, which may be resulted from infiltrating of the electrolyte and the chemical activation of the active materials ${ }^{59}$. For comparison, the battery with Celgard ${ }^{T M} 2400$ after 100 cycles shows two semicircles (Supplementary Fig. 19B). The semicircle in high frequency $\left(R_{\mathrm{sf}} / /\right.$ $\mathrm{CPE}_{\mathrm{sf}}$ ) is related to the formation of an insulating layer of solid $\mathrm{Li}_{2} \mathrm{~S}_{2} / \mathrm{Li}_{2} \mathrm{~S}$ on lithium anode 60 and the second semicircle in low frequency $\left(R_{\mathrm{ct}} / / \mathrm{CPE}_{\mathrm{ct}}\right)$ is assigned to the charge transfer resistance. On the contrary, the batteries with $n p-A N F$ membranes possess only one semicircle in the high-frequency region (red curve in Supplementary Fig. 19 and Supplementary Table. 4). Furthermore, the corresponding $R_{\mathrm{ct}}$ value is lower for $n p-A N F$ than for Celgard ${ }^{T M} 2400$, which indicates faster reaction kinetics due to the formation of the SEI film on the electrode's surface making the Li ions transport easier ${ }^{61,62}$.
Although the transport of LPS is blocked, $\mathrm{Li}^{+}$ion transport through $n p-A N F$ is not and, in fact, remains fast. $\mathrm{Li}^{+}$ion conductivity is as high as $0.24 \mathrm{mS} / \mathrm{cm}$ due to the low internal resistance, favorable electrolyte wettability, and high electrolyte uptake (Supplementary Figs. 4, 5), which translates into excellent rate performance of $\mathrm{Li}-\mathrm{S}$ cell when ion-selective when $n p$-ANF is used as ion conductor (Fig. 4D and Supplementary Fig. 20). With the current densities varied between 0.1 and 3.0C, discharge capacities of $1268,1092,969,889,703$, and $521 \mathrm{mAh} \mathrm{g}^{-1}$ were observed. When the charge/discharge rate was reduced back to $0.1 \mathrm{C}$, a capacity of $1224 \mathrm{mAh} \mathrm{g}^{-1}$ close to the original one was recovered for the cell with $n p-A N F$ whereas $931 \mathrm{mAh} \mathrm{g}^{-1}$ was observed for the cell with Celgard ${ }^{T M} 2400$ membrane. The batteries utilizing np- $A N F$ membranes display a cycle life over 3500 cycles at $3 \mathrm{C}$ (Fig. 4E) with a capacity decay as low as $0.01 \%$ per cycle (Fig. 4F). Compared to many other ion-conductive membranes used for Li-S batteries, including carbon interlayers that serve mainly as physical barriers, $n p-A N F$ is more efficient in the long-term inhibition of LPS diffusion (Supplementary Fig. 21 and Supplementary Table 5).

Moreover, to evaluate the feasibility of the $n p-A N F$ separator in electric vehicles and similarly demanding applications, the sulfur loading was increased to 3.6 and $5.8 \mathrm{mg} \mathrm{cm}^{-2}$. The batteries were still able to deliver a high initial capacities of $1142 \mathrm{mAh} \mathrm{g}^{-1}$ (3.6 $\mathrm{mg} \mathrm{cm}^{-2}$ ) and $1018 \mathrm{~mA} \mathrm{~h} \mathrm{~g}^{-1}\left(5.8 \mathrm{mg} \mathrm{cm}^{-2}\right)$ (Fig. 4G) with the corresponding areal capacities of 4.1 and $5.9 \mathrm{mAh} \mathrm{cm}^{-2}$. Based on the charge/ discharge curves (Supplementary Fig. 22A), 

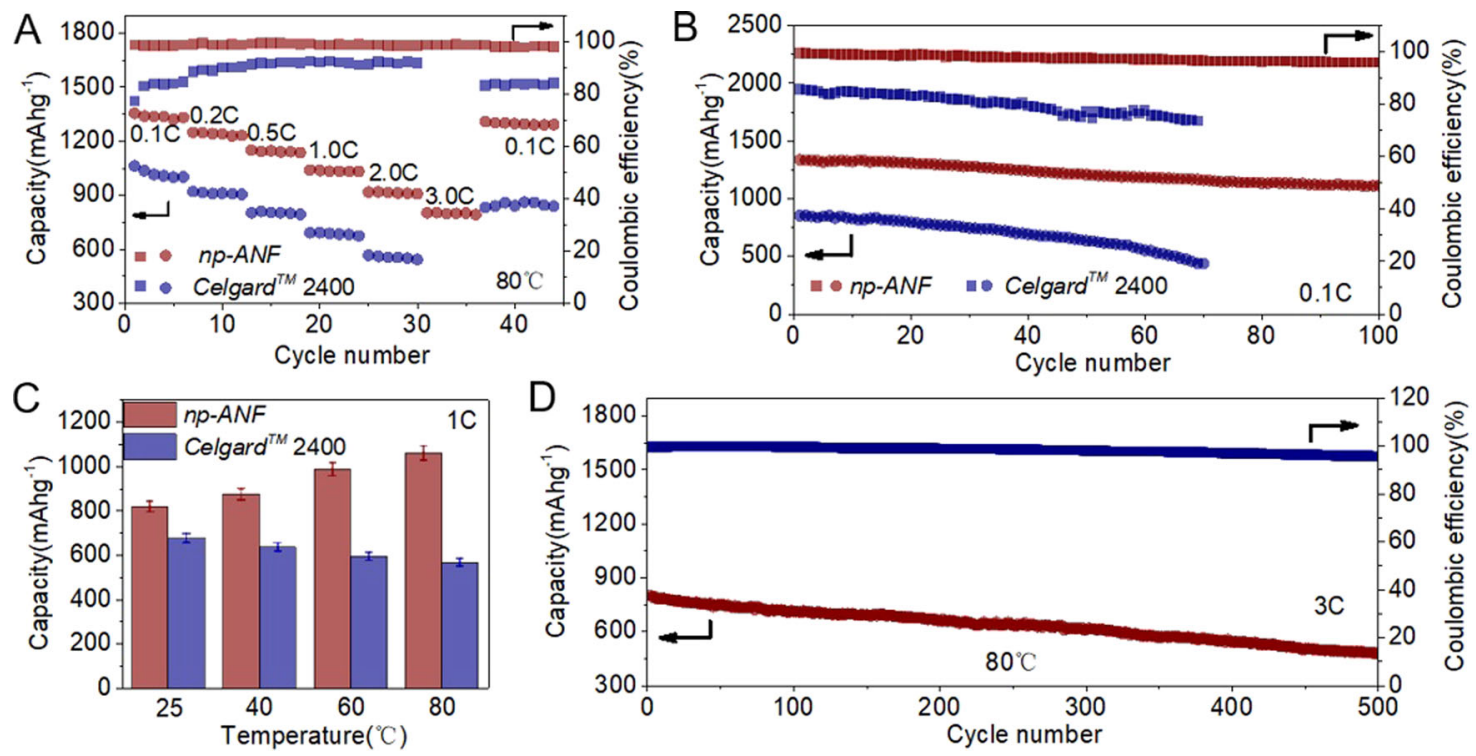

Fig. 5 Electrochemical performance of the Li-S batteries with $n p-A N F$ and Celgard ${ }^{T M} 2400$ membrane at elevated temperature of $80{ }^{\circ} \mathrm{C}$. A Rate performance of Li-S batteries ranged 0.1C to 3C with np-ANF and its comparison of Celgard ${ }^{T M} 2400$. B Cycling performance of Li-S batteries at 0.1C at $80^{\circ} \mathrm{C}$. C The capacity comparison of $n p-A N F$ and CelgardTM 2400 membrane at different temperatures. D Cycling performance Li-S batteries with $n p-A N F$ membrane at a rate of $3 \mathrm{C}$ after 500 cycles at $80^{\circ} \mathrm{C}$.

no polarization increase upon higher sulfur loading was observed. We also tested the cells with high sulfur loading for various current rates from 0.1C to 3.0C (Supplementary Fig. 22B). A high discharge capacity of $558 \mathrm{mAh} \mathrm{g}^{-1}$ at $3.0 \mathrm{C}$ was attained. Similarly to the case of $1.2 \mathrm{mg} \mathrm{cm}^{-2}$ sulfur loading, switching the charge-discharge current back recovers the capacity of the battery to $940 \mathrm{mAh} \mathrm{g}^{-1}$ even when the sulfur loading as high as $5.8 \mathrm{mg} \mathrm{cm}^{-2}$ due to effective mitigation of LPS transfer from cathode to anode. Long-term cycling for 500 cycles (initial capacity $945 \mathrm{mAh} \mathrm{g}^{-1}, 5.5 \mathrm{mAh} \mathrm{cm}^{-2}$ at $0.2 \mathrm{C}$ ) is also possible for high-sulfur cathodes (Fig. $4 \mathrm{H}$ ); their capacity is competitive or better than most Li-S cells with sulfur loading $\geq 3.0 \mathrm{mg} \mathrm{cm}^{-2}$ (Supplementary Table 6).

$n p-A N F$ membranes engender high-temperature tolerance of Li-S batteries. The tolerance of a $\mathrm{Li}-\mathrm{S}$ batteries to elevated temperatures is an important parameter determining their safety, as the increased operational temperature is accompanied with higher charge-discharge rates. Futhermore, increased operational temperature can also aggravate the dissolution of polysulfides, accelerating the consumption of active materials and the attenuation of capacity. Thus, the batteries with $n p$-ANF membranes were evaluated at $80^{\circ} \mathrm{C}$. The $n p-A N F$ cells show an increase in capacity to $1346 \mathrm{mAh} \mathrm{g}^{-1}$ at $0.1 \mathrm{C}$ (Fig. 5A) compared to room temperature cycles $\left(1268 \mathrm{~mA} \mathrm{hg}^{-1}\right)^{26,63}$. When the current density increased stepwise, the discharge capacities of the $n p$ - $A N F$ were $1249,1140,1032,916$, and $801 \mathrm{~mA} \mathrm{hg}^{-1}$ at $0.2 \mathrm{C}$, $0.5 \mathrm{C}, 1 \mathrm{C}, 2 \mathrm{C}$, and $3 \mathrm{C}$, respectively, with a capacity retention of around $60 \%$, exhibiting a much better high-temperature rate performance than that of cell with Celgard ${ }^{T M} 2400$ membranes. When the charge/discharge rate was reduced back to $0.1 \mathrm{C}$, a discharge capacity of $1302 \mathrm{mAh} \mathrm{g}^{-1}$ was observed and almost kept steady for the subsequent 100 charge-discharge cycles whereas the capacity decreased rapidly and fell to below $300 \mathrm{mAh}$ $\mathrm{g}^{-1}$ after only 60 cycles for the cell with Celgard ${ }^{T M} 2400$ membrane (Fig. $5 \mathrm{~B}$ ). The capacities of cell employing $n p-A N F$ increase due to the increased diffusion coefficient of $\mathrm{Li}^{+}$in polysulfides (Fig. 5C), whereas an opposite trend was observed for Celgard ${ }^{T M}$ 2400 membrane due to the rapid self-discharge caused by crossover of LPS. The battery with $n p-A N F$ also display long cycle life with a low-capacity decay $(0.081 \%$ per cycle) over 500 cycles at 3C and the Coulombic efficiency remain 95-99\% (Fig. 5D) at temperatures as high as $80^{\circ} \mathrm{C}$, which exceeds the state-of-the-art of Li-S batteries (Supplementary Table 7).

$\boldsymbol{n} \boldsymbol{p}$ - $\boldsymbol{A N F}$ membranes suppress $\mathrm{Li}$ dendrites. All Li metal anodes suffer from dendrite growth upon charging. To demonstrate dendrite suppression by $n p-A N F$ membrane, cyclic charge/discharge in a symmetrical $\mathrm{Li} / \mathrm{membrane} / \mathrm{Li}$ with $1 \mathrm{~mol} / \mathrm{L} \mathrm{LiCF}_{3} \mathrm{SO}_{3}$ DOL: DME $(\mathrm{v} / \mathrm{v}=1 / 1)$ cell were evaluated over $250 \mathrm{~h}$ (Fig. 6A). The cell with $n p$-ANF exhibited negligible loss or fluctuation of voltage. In contrast, the voltage of cells from Celgard ${ }^{T M} 2400$ increased over cycles, by almost $100 \%$ after $250 \mathrm{~h}$ due to dendriteinduced soft short circuit. To study the evolution of the voltage profiles in detail, the $10 \mathrm{~h} 100 \mathrm{~h}$ and sudden increase cycling of the cells with $n p-A N F$ and Celgard ${ }^{T M} 2400$ membrane were further enlarged as the insets in Fig. 6A. Flat voltage profiles at both the charging and discharging states can be retained throughout the whole cycle without obvious increases in hysteresis for cells with $n p$-ANF membranes, whereas batteries with Celgard $^{T M} 2400$ showed fluctuating voltage profiles with consistently higher overpotential at both the initial and final stages of each stripping/plating promoting the growth of dendrites. Greatly improved cycling stability was also observed with $n p$ - $A N F$ as we increased the current density to $2 \mathrm{~mA} \mathrm{~cm}^{-2}$ and $3 \mathrm{~mA} \mathrm{~cm}^{-2}$ process (Fig. 6B, C), whereas the cells with Celgard ${ }^{T M} 2400$ exhibited a gradual increase of the hysteresis. Although high rate charge/discharge cycling stimulates the dendrite growth, the surface image of lithium electrode remained consistently flat even at a high current density of $3 \mathrm{~mA} \mathrm{~cm}^{-2}$ after $250 \mathrm{~h}$ cycling (Fig. 6E). Lithium cells with Celgard ${ }^{T M} 2400$ displayed rough surface and massive formation of dendrites after $250 \mathrm{~h}$ cycling under the same conditions or even at a lower current density $1 \mathrm{~mA} \mathrm{~cm}^{-2}$ (Fig. 6F, G). At a high current density of 2 and $3 \mathrm{~mA} \mathrm{~cm}^{-2}$, extensive growth of dendrites was observed on lithium electrode surface (Fig. 6H, I and Supplementary Fig. 23). Such drastically different results further demonstrate the advantages of $n p$-ANF membranes. 

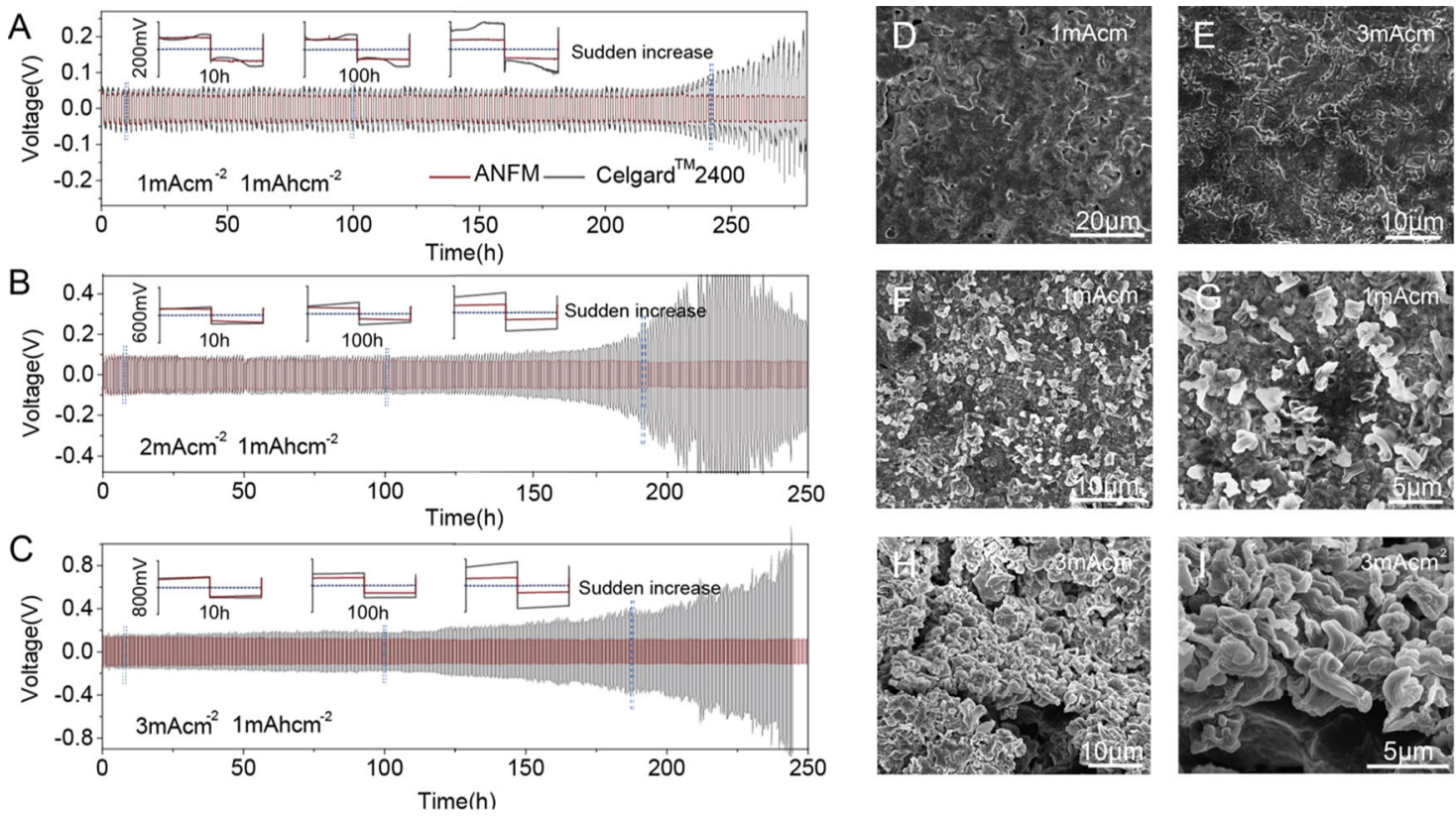

Fig. 6 Comparison of the cycling stability of the $n p-A N F$ and the Celgard ${ }^{T M} 2400$ membranes at a current density of A $1 \mathrm{~mA} \mathrm{~cm}^{-2}, \mathrm{~B}^{2} \mathrm{~mA} \mathrm{~cm}^{-2}$, and

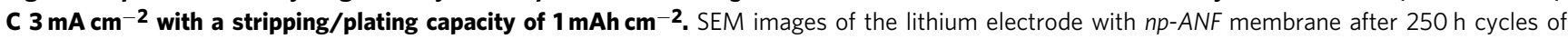
stripping/plating in $1 \mathrm{~mol} / \mathrm{L} \mathrm{LiCF}_{3} \mathrm{SO}_{3} \mathrm{DOL}$ : DME v/v =1/1) at a current density $\mathbf{D} 1 \mathrm{~mA} \mathrm{~cm}^{-2}$ and $\mathbf{E} 3 \mathrm{~mA} \mathrm{~cm}^{-2}$. SEM images of the lithium electrode with Celgard ${ }^{T M} 2400$ membrane after $250 \mathrm{~h}$ cycles of stripping/plating in $1 \mathrm{~mol} / \mathrm{L} \mathrm{LiCF} \mathrm{SO}_{3} \mathrm{DOL}: \mathrm{DME} \mathrm{V} / \mathrm{v}=1 / 1$ at a current density (F), magnified image (G) $1 \mathrm{~mA} \mathrm{~cm}^{-2}$ and $(\mathbf{H})$, and magnified image (I) $3 \mathrm{~mA} \mathrm{~cm}^{-2}$.

Multifactorial performance for $\mathrm{Li}-\mathrm{S}$ batteries with $n p-A N F$ membranes. As an example of a complex task to engineer a battery satisfying several often contrarian parameters such as high discharge rate and long cycle life, we carried out multiparameter performance assessment of $\mathrm{Li}-\mathrm{S}$ cells with $n p-A N F$ separators using glyph plots (Fig. 7). The following parameters were chosen to evaluate the state-of-the-art $\mathrm{Li}-\mathrm{S}$ batteries due to their significance to multiple technologies: initial discharge capacity at $0.1 \mathrm{C}\left(\mathrm{mAh} \mathrm{g}^{-1}\right)$; initial discharge capacity at $1.0 \mathrm{C}\left(\mathrm{mAh} \mathrm{g}^{-1}\right)$; cycle life at $1.0 \mathrm{C}$; capacity retention at $1.0 \mathrm{C}(\%)$; Coulombic efficiency (\%); maximum sulfur loading $\left(\mathrm{mg} / \mathrm{cm}^{2}\right)$; maximum operational temperature $\left({ }^{\circ} \mathrm{C}\right)$. Since battery capabilities increase with the increase of these metrics, the total area encircled by the glyph plot can be used as a cumulative capability criterion (CCC, \%) to compare and optimize the batteries. CCC is enumerated as a percentage of the area encircled by the glyph plot from the maximum possible for the capability-relevant range of properties (Fig. 7). When feasible, it can also include uncertainty intervals based on the reported measurement errors. Interdependent variations of different parameters obtained for different versions of similar materials or different operation conditions may also be included. Here we analyzed the data for $\mathrm{Li}-\mathrm{S}$ batteries with comparable data sets. The assessment shows that cells with $n p$ ANF membranes have across-the-board performance exceeding the current state-of-the-art in Li-S batteries. When needed, a longer list of the parameters can be selected, albeit methodology will remain the same. For the broader use of CCC analysis, the incorporation of the variability range as we included for our data is recommended. It can be particularly important for the large parameter sets when several materials can be similar in the CCC analysis so that several engineering options can be determined.

\section{Discussion}

Biomimetic $n p-A N F$ membranes integrating ion-channel-line nanoscale pores and cartilage-like architecture can effectively block LPS transport while remaining transparent to $\mathrm{Li}^{+}$ions. In addition to LPS screening based on ion size enabled by the $1 \mathrm{~nm}$ pores in $n p$-ANF, surface charge density on the walls of the pores is enhanced by adsorption of LPS that repell similar ions. The combination of a highly interconnected network of percolated nanofibers and intrinsic materials properties of aramid simultaneously enable effective suppression of dendrites and long-term operation of the batteries at elevated temperatures. The multifactorial engineering of $n p$-ANF membranes encompassing narrow pore size, negative charges, high mechanical and thermal properties collectively lead to the promising electrochemical performance in Li-S batteries exceeding the current state of the art comparing several singular parameters and across-the-board performance. The simplicity of $A N F$ fabrication and availability of parent material Kevlar as a recyclable polymer enables their broad utilization in different energy technologies.

\section{Methods}

Preparation of the ANFs and ion-selective membranes from them. To prepare the ANF dispersion, the fabrication method is reported previously ${ }^{49} .1 \mathrm{~g}$ of bulk Kevlar 69 (from Thread Exchange) and $1.5 \mathrm{~g} \mathrm{KOH}$ were added into $500 \mathrm{~mL}$ of dimethyl sulfoxide (DMSO) which was magnetically stirred for two weeks at room temperature forming a dark red solution of ANF. For LBL assembly of nanoporous ANF-based membranes abbreviated here as $n p-A N F$, microscope glass slides were cleaned in piranha solution $\left(3: 1 \mathrm{H}_{2} \mathrm{SO}_{4} / \mathrm{H}_{2} \mathrm{O}_{2}\right)$ for $24 \mathrm{~h}$, followed by thorough rinsing with deionized water before use. After that, setting a clean piece of the glass slide on the disk of the spin coater, $2 \mathrm{~mL}$ of ANF (2 wt\%) solution was dropped and spin-coated at $1500 \mathrm{rpm}$ for $30 \mathrm{~s}$. After spin coating, the membrane was immediately put into DI water to remove the DMSO and then dried at $70{ }^{\circ} \mathrm{C}$ in oven $10 \mathrm{~min}$. Then the glass slide was dipped into $0.1 \mathrm{wt} \%$ poly(diallyldimethylammonium chloride) (PDDA) solution to change the charge for $1 \mathrm{~min}$ and rinsed with water for $2 \mathrm{~min}$ before air drying. This sequence of steps was repeated three times and the last layer is ANF. It should be noted that the thickness of membrane can be ranged by increase or decrease the membrane's layer. The membrane is peeled from the substrate by immersing in $0.1 \%$ (hydrofluoric acid) HF solution. The remaining chemicals were purchased from Sigma Aldrich without further purification. ANF dispersion with similar composition and characteristics of the nanofibers can also be made from previously used Kevlar ${ }^{\mathrm{TM}}$ fabrics, fibers, and yarns. The process of their recycling into ANF will include the process of dissolution in DMSO in presence of $\mathrm{KOH}$ identical to that described above. 

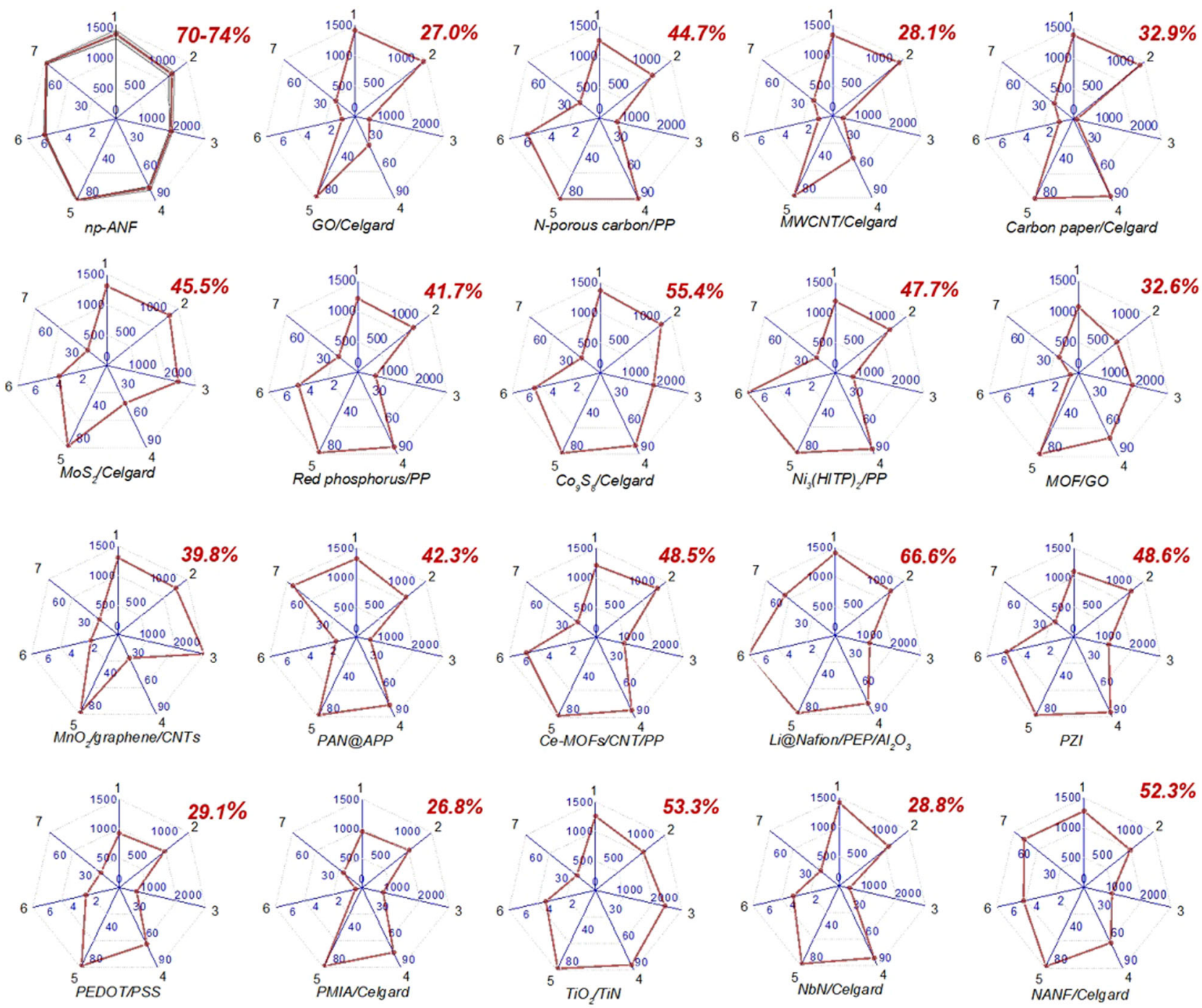

1. Discharge Capacity at $0.1 \mathrm{C}\left(\mathrm{mAhg}^{-1}\right) ; 2$. Discharge Capacity at $1.0 \mathrm{C}\left(\mathrm{mAhg}^{-1}\right) ; 3$. Cycle number at $1.0 \mathrm{C} ; 4$. Capacity Retention at $1.0 \mathrm{C}$

5. Coulombic Efficiency $(\%)$; 6. Maximum Sulfur Loading $\left(\mathrm{mg} / \mathrm{cm}^{2}\right)$; 7. Maximum Operational Temperature $\left({ }^{\circ} \mathrm{C}\right)$

Fig. 7 Multiparameter comparison of various for Li-S batteries based on glyph plots and cumulative capability criterion (CCC). The value of CCC is given in the top red corner of each glyph plot. The detailed data set for the plots are provided in Supplementary Information in Table S8. The gray area in $n p-A N F$ in the top left corner is the variability range for our measurements. For many performance parameters, the error value was not reported.

Structural characterization. The morphology of the Li dendrite, Celgard ${ }^{T M} 2400$, and $n p-A N F$ membrane were inspected with a scanning electron microscope (SEM, FEI Nova Nanolab dual-beam FIB). The $n p-A N F$ before and after $\mathrm{Li}_{2} \mathrm{~S}_{4}$ adsorption was measured by Raman spectra (LabRAM HR 800 spectrometer at $785 \mathrm{~nm}$ ) and X-ray photoelectron spectra (XPS, Thermo Fisher Scientific, USA. The data were obtained in an XPS system, via monochromatic $\mathrm{Al} \mathrm{Ka}$ radiation with a pass energy of $50 \mathrm{eV}$.) Note: The $n p-A N F$ membrane was immersed into $0.5 \mathrm{M} \mathrm{Li}_{2} \mathrm{~S}_{4}$ in $\mathrm{DOL} /$ DME for $10 \mathrm{~h}$ at room temperature $\left(25^{\circ} \mathrm{C}\right)$ followed by repeated pure DOL/DME solution washing to remove any residual LPS and then dried in glovebox.

Quantachrome Autosorb 6B system was used to characterize the pore width of the $n p-A N F$ membrane using nitrogen sorption under $77.4 \mathrm{~K}$. The pore size distributions of the $n p-A N F$ membrane were calculated by BJH methods. The contact angle was measured by Cam-plus Micrometer with the sessile drop technique.

Electrolyte uptake tests were conducted by measuring the weights of the sample before $\left(W_{\text {dry }}\right)$ and after $\left(W_{\text {wet }}\right)$ soaking in liquid electrolyte $(1 \mathrm{M}$ LiTFSI, DOL $/ \mathrm{DME}(\mathrm{v} / \mathrm{v}=1 / 1)$ for $2 \mathrm{~h}$ and calculated according to equation:

$$
\text { Electrolyte uptake }=\frac{W_{\text {wet }}-W_{\text {dry }}}{W_{\text {dry }}} \times 100 \%
$$

For dimensional and volumetric change analysis, sample thickness was measured using a caliper, and the area was measured using digital imaging before and after electrolyte uptake.
The mechanical tests of the membranes were performed on a TA XT Plus Texture Analyzer (Stable Micro Systems Ltd.) instrument at room temperature and high temperature of $80^{\circ} \mathrm{C}$, with the test of longitudinal direction carried out at a rate of $2 \mathrm{~mm} \mathrm{~min}^{-1}$. The film was cut into rectangular strips of $20 \mathrm{~mm} \times 5 \mathrm{~mm}$, and twenty samples were tested in each case. For wet conditions, the sample was soaked into electrolyte solution (1 M LiTFSI, DOL /DME $(\mathrm{v} / \mathrm{v}=1 / 1)$ for $2 \mathrm{~h}$ before testing. Dry conditions did not soak into the electrolyte solution. The mechanical performance of the separator after the electrochemical testing also have been tested. The separator was taken from cells that have been evaluated in a symmetrical $\mathrm{Li} /$ membrane/Li system over $250 \mathrm{~h}$ at a current density of $1 \mathrm{~mA} \mathrm{~cm}^{-2}$ with the electrolyte of $1 \mathrm{~mol} / \mathrm{L} \mathrm{LiCF}_{3} \mathrm{SO}_{3}$ DOL: DME $(\mathrm{v} / \mathrm{v}=1 / 1)$, The nano-indentation tests of membranes were performed on a Bruker Hysitron TI980 instrument at room temperature, and five points were tested in each sample.

The thermal stability of membrane was analyzed by TA Instruments Discovery thermogravimetric analyzer (TGA) with a temperature ramp to 700 at $10^{\circ} \mathrm{C} \mathrm{min}^{-1}$ in nitrogen at a flow rate of $30 \mathrm{~mL} \mathrm{~min}^{-1}$ and DSC with a temperature ramp to 500 at $10^{\circ} \mathrm{C} \mathrm{min}-1$ in nitrogen at a flow rate of $30 \mathrm{~mL} \mathrm{~min}^{-1}$.

Visualization of ion-selectivity. The electrochemical cell test that cab visualize LPS blocking was carried out in an H-type glass cell to examine the properties of the membrane. Celgard ${ }^{T M} 2400$ and $n p$-ANF membranes were set in the middle of glass cell. The left chamber was filled with $0.5 \mathrm{M} \mathrm{Li}_{2} \mathrm{~S}_{4}$ solution with DOL /DME $(\mathrm{v} / \mathrm{v}=1: 1)$ as the solvent, while the right chamber was only filled with DOL/DME 
solvent $(\mathrm{v} / \mathrm{v}=1: 1)$. The $\mathrm{Li}_{2} \mathrm{~S}_{4}$ was prepared by a synproportionation reaction ${ }^{64}$ between $\mathrm{Li}_{2} \mathrm{~S}$ and $\mathrm{S}$ with a mole ratio of 1:2.

Computation for the transport of charged ion species. To elucidate the mechanism of selective ion transport through the $n p-A N F$ membrane, we have simplified the system as a single nanopore channel of the np-ANF membrane connecting two reservoirs. The $2 \mathrm{D}$ nanochannel model was implemented in the commercial finite element solver, COMSOL Multiphysics.

Model geometry. The system consists of electrolyte reservoirs connecting through the $10 \mathrm{~nm}$ long nanochannel. The diameter of the channel was set to $1 \mathrm{~nm}$ based on the experimental pore size determined by the BJH analysis (Supplementary Figs. 5, 6). Both the reservoirs and nanochannel are represented by dielectric blocks with the electrolyte.

Governing equations. The dynamics of our system can be solved by the coupled Poisson, Nernst-Planck, and Navier-Stokes equations, a well-known set of partial differential equations that represents the electrostatic field, the ionic flux, and the fluid flow, respectively $65-68$.

Electrostatic field. The electrostatic potential of the system has evaluated using Poisson's equation, solved using the electrostatic interface in COMSOL. For the potential, Poisson's equation states:

$$
\nabla \cdot\left(\varepsilon_{0} \varepsilon_{r} \nabla \phi\right)=-\rho,
$$

where $\phi$ is the electric potential, $\varepsilon_{0}$ the vacuum permittivity $\left(8.85419 \times 10^{-12} \mathrm{~F} \cdot \mathrm{m}^{-1}\right)$, $\varepsilon_{r}$ relative permittivity of the material, and $\rho$ total charge density which was derived from zeta potential measurements.

Ionic flux. The total ionic flux $J_{i}$ of each ion, $i$, is governed by the Nernst-Planck equation, which can be expressed as the sum of diffusive, electrophoretic, and convective fluxes:

$$
J_{i}=-\left[D_{i} \nabla c_{i}+z_{i} \mu_{t} c_{i} \nabla \phi-\boldsymbol{u} c_{i}\right],
$$

with $D_{i}$ being the ion diffusion coefficient, $c_{i}$ the ion concentration, $z_{i}$ the ion charge number, $\mu_{i}$ the electrophoretic mobility of ion $i$, and $\boldsymbol{u}$ the fluid velocity.

And assuming no homogeneous reaction in the electrolyte, at steady state, the governing equations for the species become:

$$
\frac{\delta c_{i}}{\delta t}=-\nabla \cdot J_{i}=0,
$$

Fluid flow. The fluid flow model is set as an incompressible flow regulated by the Navier-Stokes equations:

$$
£ \frac{\delta \boldsymbol{u}}{\delta t}+(\boldsymbol{u} \cdot \nabla)(£ \boldsymbol{u})=\nabla \cdot[-p \mathbf{I}+\mathbf{K}]+\mathbf{F},
$$

with the hydrodynamic stress tensor, $\mathbf{K}=\eta\left[\nabla \boldsymbol{u}+(\nabla \boldsymbol{u})^{\mathrm{T}}\right]$ and the continuity equations, $£ \nabla \cdot \boldsymbol{u}=0$, where $£$ is the fluid density, $\eta$ the dynamic viscosity, $p$ the pressure, $\mathbf{F}$ is the volume force vector.

Multiphysics coupling. Other than potential coupling from electrostatic to the transport of diluted species interface, space charge density coupling has been added by defining dependence of the space charge density (SI unit: $\mathrm{C} / \mathrm{m}^{3}$ ), $\rho$, on the ion concentrations:

$$
\rho=F \sum_{i} z_{i} c_{i}
$$

with $F$ Faraday's constant $\left(96485.33 \mathrm{C} \cdot \mathrm{mol}^{-1}\right)$, and $c_{i}$ the ion concentration and $z_{i}$ ion charge number of ion $i$.

Electrochemical performance tests. Standard 2032-coin cells (MTI) were used to evaluate the electrochemical performance of the $n p$-ANF membrane-incorporated Li-S batteries. The $\mathrm{C} / \mathrm{S}$ cathode materials were fabricated with a typical melt-diffusion strategy. The nanocarbon was firstly mixed with sulfur powder with a mass ratio of $3: 6$ by milling. The mixture was subsequently placed in a sealed flask at $155^{\circ} \mathrm{C}$ for $10.0 \mathrm{~h}$ to incorporate $\mathrm{S}$ into the carbonaceous matrix. The cathode slurry was then prepared by mixing $90 \mathrm{wt} \%$ sulfur/carbon composite and $10 \%$ poly(vinylidene fluoride) binder in N-methylpyrrolidone (NMP) solvent dispersant. The cathode was constructed by coating the slurry on aluminum foil and drying at $60^{\circ} \mathrm{C}$ at vacuum oven for $24.0 \mathrm{~h}$. The sulfur loading was $1.2 \mathrm{mg} \mathrm{cm}^{-2}$ for the regular tests and around 3.6 and $5.8 \mathrm{mg} \mathrm{cm}^{-2}$ for the high sulfur loading test. Cathode samples were punched into $16 \mathrm{~mm}$ diameter circles. The metallic lithium foil (thickness $0.5 \mathrm{~mm}$, diameter $16 \mathrm{~mm}$ ) purchased from MTI Corporation was directly used as the anode. Then $1 \mathrm{M}$ LiTFSI solution in DOL/DME $(\mathrm{v} / \mathrm{v}=1 / 1)$ was used for the cells and the electrolyte/sulfur ratio was controlled at 10:1 $\left(\mu \mathrm{L} \mathrm{mg}^{-1}\right)$. The separator used in the cell were routine $\mathrm{Cel}$ gard $^{T M} 2400$ (thickness $25 \mu \mathrm{m}$ ) or $n p$-ANF (thickness $5.8 \mu \mathrm{m}$ ). Separator samples were punched into $19 \mathrm{~mm}$ diameter circles. The coin cells were tested in galvanostatic mode at various currents within a voltage range of 1.7-2.8 $\mathrm{V}$ using LAND-CT2001A batterytesting instrument. Both CV and EIS were performed on an Autolab (Autolab Potentiastat and Solartron 1260 frequency response analyzer). The EIS carried out in the range from $100 \mathrm{kHz}$ to $0.05 \mathrm{~Hz}$ with potential amplitude of $20 \mathrm{mV}$. The resulting Nyquist plots were fitted to an equivalent circuit where ionic conductivity was then calculated from the equation: $\sigma=L / R_{\mathrm{b}} A$, where $L$ is the thickness of the film, $R_{\mathrm{b}}$ is the bulk resistance, and $\mathrm{A}$ is the contact area of film. The $\mathrm{CV}$ was scanned at a rate range of $0.10-0.50 \mathrm{mV} \mathrm{s}^{-1}$. LSV was conducted using an Autolab. The separator was placed in between a stainless-steel electrode and a Li foil working electrode (both $16 \mathrm{~mm}$ in diameter) with $1 \mathrm{M}$ LiTFSI in DOL/DME $(\mathrm{v} / \mathrm{v}=1 / 1)$ as the electrolyte. The cell was then held at $0 \mathrm{~V}$ for $5 \mathrm{~min}$ and then ramped from 0 to $4 \mathrm{~V}$ at a scan rate of $0.5 \mathrm{mV} \mathrm{s}^{-1}$ The capacities were calculated based on the mass of sulfur in the cathode.

The lithium-ion diffusion coefficient $D_{\mathrm{Li}}\left(\mathrm{cm}^{2} \mathrm{~s}^{-1}\right)$ was evaluated by cyclic voltammetry and calculated according to the Randles-Sevick equation:3,56,69

$$
I_{\mathrm{p}}=2.69 \times 10^{5} n^{1.5} A D_{\mathrm{Li}^{+}}^{0.5} C v^{0.5}
$$

in which $I_{\mathrm{p}}(\mathrm{A})$ is the peak current, $n$ represents the number of electrons of in the reaction (for Li-S batteries, $n=2), A\left(\mathrm{~cm}^{2}\right)$ indicates the electrode area $\left(1.54 \mathrm{~cm}^{2}\right.$ here), $C_{\mathrm{Li}+}(\mathrm{mol} / \mathrm{mL})$ means the lithium-ion concentration $(0.1 \mathrm{~mol} / \mathrm{L})$ in the electrolyte, and $v$ is the scanning rate $\left(\mathrm{Vs}^{-1}\right)$.

The $\mathrm{Li}^{+}$transference number $\left(t_{\mathrm{Li}+}\right)$ for different separators was evaluated by a potentiostatic polarization method of a constant potential at $10 \mathrm{mV}$ was applied for $10,000 \mathrm{~s}$ to record the current at initial and steady-state. Each membrane was separately sandwiched between two lithium metal electrodes in a coin-type cell (CR2023) and saturated with $1 \mathrm{M} \mathrm{LiTFSI} \mathrm{in} \mathrm{DOL/DME} \mathrm{(v/v} \mathrm{=} \mathrm{1:1)} \mathrm{electrolyte.} \mathrm{The}$ $\mathrm{Li}^{+}$transference number was calculated from the ratio of steady-state current to initial state current according to the following equation:

$$
t_{\mathrm{Li}+}=I_{\mathrm{s}} / I_{0}
$$

where $t_{\mathrm{Li}+}$ is transference number, while $I_{\mathrm{s}}$ and $I_{0}$ represent the current at the steady state and initial state, respectively.

The relationship between Young's Modulus and dendrite suppression. The model developed by Monroe and Newman shows that dendrites become unstable when the interfacial stability parameter $\Delta \mu$ changes from positive to negative ${ }^{27}$. For the interface between lithium and polyethylene oxide (PEO), this transition occurs when

$$
G_{\mathrm{PEO}} / G_{\mathrm{Li}}=1.65,
$$

where $G_{\mathrm{PEO}}$ and $G_{\mathrm{Li}}$ are shear moduli of the polymeric electrolyte and lithium metal, respectively.

While the shear modulus $G$ is related to Young's modulus, $E$, as

$$
G=0.5 E /(1+\nu)
$$

where $v$ is the Poisson's ratio of the material. In case of metallic Li and PEO, $v_{\mathrm{Li}}=$ $\sim 0.4$ and $v_{\mathrm{PEO}}=0.33$, respectively, leading to $G_{\mathrm{Li}}=0.5 E_{\mathrm{Li}} /(1+0.4)$ and $G_{\mathrm{PEO}}=$ $0.5 E_{\mathrm{PEO}} /(1+0.33)$. Then, the threshold condition $G_{\mathrm{PEO}} / G_{\mathrm{Li}}=1.65$ for $\mathrm{Li} / \mathrm{PEO}$ interphase transforms into $1.4 E_{\mathrm{PEO}} / 1.33 E_{\mathrm{Li}}=1.65$ or

$$
E_{\mathrm{PEO}} / E_{\mathrm{Li}}=1.53
$$

Note that the threshold condition in Eq. 3 is dependent on Poisson's ratios of materials on both sides of the interface, as can be seen by examining Figs. 3, 4, and 6 in the original paper by Monroe and Newman ${ }^{27}$. However, the current battery literature conceptualizes Eq. 3 as a condition for dendrite suppression not just for PEO but for any material disregarding the dependence of the $\Delta \mu$ threshold and respect $G_{\text {polymer }} / G_{\mathrm{Li}}$ on Poisson's ratio of the polymer. Examples of such approaches in the current electrochemical literature are multiple ${ }^{70-75}$.

While being a deviation from the original expression for displacement functions (Eq. 16 from 2005 Monroe-Newman study) ${ }^{27}$, such simplification is driven by materials properties used in practice is justified because the Poisson's ratio of solid semi-crystalline and amorphous polymers vary in a narrow range of values ${ }^{76-78}$. The same logical path can be taken considering Eq. 5 leading to a modification of the original expression Eq. 3 as $E_{\text {polymer }} / E_{\mathrm{Li}}=1.53$. Note that this expression is consistent with the Monroe-Newman framework of continuum mechanics and the assumption of small deformations and Hookean-elastic regime as well as subsequent elaborations on the theory of dendrite growth ${ }^{27,79}$. Some of these points were also discussed in our prior publication ${ }^{39}$.

\section{Data availability}

The experiment data that support the findings of this study are available from the corresponding authors upon reasonable requests.

Received: 16 July 2021; Accepted: 16 December 2021; Published online: 12 January 2022

\section{References}

1. Zhou, G., Paek, E., Hwang, G. S. \& Manthiram, A. Long-life Li/polysulphide batteries with high sulphur loading enabled by lightweight three-dimensional nitrogen/sulphur-codoped graphene sponge. Nat. Commun. 6, 1-11 (2015). 
2. Vijayakumar, M. et al. Molecular structure and stability of dissolved lithium polysulfide species. Phys. Chem. Chem. Phys. 16, 10923-10932 (2014).

3. Bai, S., Liu, X., Zhu, K., Wu, S. \& Zhou, H. Metal-organic framework-based separator for lithium-sulfur batteries. Nat. Energy 1, 16094 (2016).

4. Conder, J. et al. Direct observation of lithium polysulfides in lithium-sulfur batteries using operando X-ray diffraction. Nat. Energy 2, 1-7 (2017).

5. Manthiram, A., Fu, Y., Chung, S. H., Zu, C. \& Su, Y. S. Rechargeable lithium-sulfur batteries. Chem. Rev. 114, 11751-11787 (2014).

6. Sun, Z. et al. Conductive porous vanadium nitride/graphene composite as chemical anchor of polysulfides for lithium-sulfur batteries. Nat. Commun. 8 , 1-8 (2017).

7. Ji, X., Lee, K. T. \& Nazar, L. F. A highly ordered nanostructured carbon-sulphur cathode for lithium-sulphur batteries. Nat. Mater. 8, 500-506 (2009).

8. Yin, L., Wang, J., Lin, F., Yang, J. \& Nuli, Y. Polyacrylonitrile/graphene composite as a precursor to a sulfur-based cathode material for high-rate rechargeable Li-S batteries. Energy Environ. Sci. 5, 6966-6972 (2012).

9. Chen, S. et al. Nanostructured polyaniline-decorated Pt/C@PANI core-shell catalyst with enhanced durability and activity. J. Am. Chem. Soc. 134, 13252-13255 (2012).

10. Demir-Cakan, R. et al. Cathode composites for Li-S batteries via the use of oxygenated porous architectures. J. Am. Chem. Soc. 133, 16154-16160 (2011).

11. Zheng, J. et al. Lewis acid-base interactions between polysulfides and metal organic framework in lithium-sulfur batteries. Nano Lett. 14, 2345-2352 (2014).

12. Zhou, W., Yu, Y., Chen, H., Disalvo, F. J. \& Abruña, H. D. Yolk-shell structure of polyaniline-coated sulfur for lithium-sulfur batteries. JACS 135, 16736-16743 (2013).

13. Liu, Y., Li, G., Fu, J., Chen, Z. \& Peng, X. Strings of porous carbon polyhedrons as self-standing cathode host for high-energy-density lithium-sulfur batteries. Angew. Chem. Int. Ed. 56, 6176-6180 (2017)

14. Wang, M. et al. Facile method to functionalize graphene oxide nanoribbons and its application to poly(p-phenylene benzobisoxazole) composite. Compos. Sci. Technol. 165, 124-130 (2018).

15. Huang, J. Q., Zhang, Q. \& Wei, F. Multi-functional separator/interlayer system for high-stable lithium-sulfur batteries: Progress and prospects. Energy Storage Mater. 1, 127-145 (2015).

16. Chung, S. H., Han, P., Singhal, R., Kalra, V. \& Manthiram, A. Electrochemically stable rechargeable lithium-sulfur batteries with a microporous carbon nanofiber filter for polysulfide. Adv. Energy Mater. 5, 1-12 (2015).

17. Bauer, I., Thieme, S., Brückner, J., Althues, H. \& Kaskel, S. Reduced polysulfide shuttle in lithium-sulfur batteries using Nafion-based separators. J. Power Sources 251, 417-422 (2014).

18. Wang, W., Christensen, R., Curtis, B., Martin, S. W. \& Kieffer, J. A new model linking elastic properties and ionic conductivity of mixed network former glasses. Phys. Chem. Chem. Phys. 20, 1629-1641 (2018).

19. Peng, H. J. et al. A cooperative interface for highly efficient lithium-sulfur batteries. Adv. Mater. 28, 9551-9558 (2016).

20. Zhang, Z., Lai, Y., Zhang, Z., Zhang, K. \& Li, J. $\mathrm{Al}_{2} \mathrm{O}_{3}$-coated porous separator for enhanced electrochemical performance of lithium sulfur batteries. Electrochim. Acta 129, 55-61 (2014).

21. Li, W. et al. $\mathrm{V}_{2} \mathrm{O}_{5}$ polysulfide anion barrier for long-lived Li-S batteries. Chem. Mater. 26, 3404-3410 (2014).

22. Obeid, E. M. H., Adams, M. A. \& Newman, J. H. Mechanical properties of articular cartilage in knees with unicompartmental osteoarthritis. J. Bone Jt. Surg. 76-B, 315 (1994).

23. Sharma, A. et al. Strain-controlled criticality governs the nonlinear mechanics of fibre networks. Nat. Phys. 12, 584-587 (2016).

24. Xu, Q., Hu, G. C., Bi, H. L. \& Xiang, H. F. A trilayer carbon nanotube $/ \mathrm{Al}_{2} \mathrm{O}_{3} /$ polypropylene separator for lithium-sulfur batteries. Ion 21, 981-986 (2015).

25. Oh, Y. S. et al. Janus-faced, dual-conductive/chemically active battery separator membranes. Adv. Funct. Mater. 26, 7074-7083 (2016).

26. Lei, T. et al. A nonflammable and thermotolerant separator suppresses polysulfide dissolution for safe and long-cycle lithium-sulfur batteries. $A d v$ Energy Mater. https://doi.org/10.1002/aenm.201802441 (2018).

27. Monroe, C. \& Newman, J. The impact of elastic deformation on deposition kinetics at lithium/polymer interfaces. J. Electrochem. Soc. 152, A396-A404 (2005).

28. Yang, B. et al. Advanced separators based on aramid nanofiber (ANF) membranes for lithium-ion batteries: a review of recent progress. J. Mater. Chem. A 9, 12923-12946 (2021).

29. Cao, R., Xu, W., Lv, D., Xiao, J. \& Zhang, J. Anodes for rechargeable lithium-sulfur batteries. Adv. Energy Mater. 5, 1402273 (2015).

30. Maroudas, A. \& Evans, H. A study of ionic equilibria in cartilage. Connect. Tissue Res. 1, 69-77 (1972).
31. Holder, A. J. et al. Control of collagen gel mechanical properties through manipulation of gelation conditions near the sol-gel transition. Soft Matter 14, 574-580 (2018)

32. Yang, Z. et al. Electrochemical energy storage for green grid. Chem. Rev. 111, 3577-3613 (2011)

33. Xu, L., Zhao, X., Xu, C. \& Kotov, N. A. Water-rich biomimetic composites with abiotic self-organizing nanofiber network. Adv. Mater. 30, 1703343 (2018).

34. Zhang, H. et al. Graph theoretical design of biomimetic aramid nanofiber composites as insulation coatings for implantable bioelectronics. MRS Bull. https://doi.org/10.1557/s43577-021-00071-x (2021).

35. Flouda, P. et al. Branched aramid nanofiber-polyaniline electrodes for structural energy storage. Nanoscale 12, 16840-16850 (2020).

36. Kwon, S. R. et al. Mechanically strong graphene/aramid nanofiber composite electrodes for structural energy and power. ACS Nano 11 6682-6690 (2017).

37. Wang, M. et al. Aramid nanofiber-based porous membrane for suppressing dendrite growth of metal-ion batteries with enhanced electrochemistry performance. Chem. Eng. J. 426, 131924 (2021).

38. Patel, A. et al. High modulus, thermally stable, and self-extinguishing aramid nanofiber separators. ACS Appl. Mater. Interfaces 12, 25756-25766 (2020).

39. Tung, S. O., Ho, S., Yang, M., Zhang, R. \& Kotov, N. A. A dendritesuppressing composite ion conductor from aramid nanofibres. Nat. Commun. 6, 6152 (2015).

40. Wang, M. et al. Biomorphic structural batteries for robotics. Sci. Robot. 5, eaba1912 (2020).

41. Wang, M. et al. Biomimetic solid-state $\mathrm{Zn} 2+$ electrolyte for corrugated structural batteries. ACS Nano 13, 1107-1115 (2019).

42. Zheng, S., Zhang, H., Fan, J., Xu, Q. \& Min, Y. Improving electrochemical performance and safety of lithium-sulfur batteries by a "Bulletproof Vest". ACS Appl. Mater. Interfaces 12, 51904-51916 (2020).

43. Jiang, C., Markutsya, S., Pikus, Y. \& Tsukruk, V. V. Freely suspended nanocomposite membranes as highly sensitive sensors. Nat. Mater. 3, 721-8 (2004).

44. Ariga, K., Vinu, A., Yamauchi, Y., Ji, Q. \& Hill, J. P. Nanoarchitectonics for mesoporous materials. Bull. Chem. Soc. Jpn. 85, 1-32 (2012).

45. Lvov, Y., Yamada, S. \& Kunitake, T. Non-linear optical effects in layer-bylayer alternate films of polycations and an azobenzene-containing polyanion. Thin Solid Films 300, 107-112 (1997).

46. Li, C. et al. Polysulfide-blocking microporous polymer membrane tailored for hybrid Li-sulfur flow batteries. Nano Lett. 15, 5724-5729 (2015).

47. Murugesan, V. et al. Elucidating the solvation structure and dynamics of lithium polysulfides resulting from competitive salt and solvent interactions. Chem. Mater. 29, 3375-3379 (2017).

48. Khurana, R., Schaefer, J. L., Archer, L. A. \& Coates, G. W. Suppression of lithium dendrite growth using cross-linked polyethylene/poly(ethylene oxide) electrolytes: A new approach for practical lithium-metal polymer batteries. J. Am. Chem. Soc. 136, 7395-7402 (2014).

49. Yang, M. et al. Dispersions of aramid nanofibers: a new nanoscale building block. ACS Nano 5, 6945-6954 (2011).

50. Koktysh, D. S. et al. Biomaterials by design: Layer-by-layer assembled ionselective and biocompatible films of $\mathrm{TiO} 2$ nanoshells for neurochemical monitoring. Adv. Funct. Mater. 12, 255-265 (2002).

51. Harris, J. J., Stair, J. L. \& Bruening, M. L. Layered polyelectrolyte films as selective, ultrathin barriers for anion transport. Chem. Mater. https://doi.org/ $10.1021 / \mathrm{cm} 0001004$ (2000).

52. Kowalczyk, S. W., Blosser, T. R. \& Dekker, C. Biomimetic nanopores: Learning from and about nature. Trends Biotechnol. 29, 607-614 (2011).

53. Gouaux, E. M. R., Gouaux, E., \& Mackinnon, R. Principles of selective ion transport in channels and pumps. Science 310, 1461-5 (2005)

54. Ihrner, N., Johannisson, W., Sieland, F., Zenkert, D. \& Johansson, M. Structural lithium ion battery electrolytes via reaction induced phaseseparation. J. Mater. Chem. A 5, 25652-25659 (2017).

55. Tao, X. et al. Balancing surface adsorption and diffusion of lithium-polysulfides on nonconductive oxides for lithium-sulfur battery design. Nat. Commun. 7, 1-9 (2016).

56. Wang, J. et al. Towards a safe lithium-sulfur battery with a flame-inhibiting electrolyte and a sulfur-based composite cathode. Angew. Chem. - Int. Ed. 53, 10099-10104 (2014).

57. Ghazi, Z. A. et al. MoS2/Celgard separator as efficient polysulfide barrier for long-life lithium-sulfur batteries. Adv. Mater. 29, 1606817 (2017)

58. Qie, L. \& Manthiram, A. A facile layer-by-layer approach for high-arealcapacity sulfur cathodes. Adv. Mater. https://doi.org/10.1002/adma.201405689 (2015).

59. Song, R. et al. A trilayer separator with dual function for high performance lithium-sulfur batteries. J. Power Sources 301, 179-186 (2016) 
60. Sun, J. et al. Entrapment of polysulfides by a black-phosphorus-modified separator for lithium-sulfur batteries. Adv. Mater. 28, 9797-9803 (2016).

61. Gu, X. et al. Microporous bamboo biochar for lithium-sulfur batteries. Nano Res. 8, 129-139 (2015).

62. Peng, H. J. et al. Janus separator of polypropylene-supported cellular graphene framework for sulfur cathodes with high utilization in lithium-sulfur batteries. Adv. Sci. 3, 1-11 (2015).

63. Zhou, Z. et al. A multifunctional separator enables safe and durable lithium/ magnesium-sulfur batteries under elevated temperature. Adv. Energy Mater. 10, $1902023(2020)$

64. Sun, J. et al. Towards a reliable Li-metal-free LiNO3-free Li-ion polysulphide full cell: Via parallel interface engineering. Energy Environ. Sci. 11, 2509-2520 (2018).

65. Wang, J., Zhang, M., Zhai, J. \& Jiang, L. Theoretical simulation of the ion current rectification (ICR) in nano-pores based on the Poisson-Nernst-Planck (PNP) model. Phys. Chem. Chem. Phys. 16, 23-32 (2014).

66. Axelssonc, O., He, X. \& Neytcheva, M. Numerical solution of the timedependent Navier-Stokes equation for variable density-variable viscosity. Part I. Math. Model. Anal. 20, 232-260 (2015).

67. Cervera, J., Schiedt, B. \& Ramírez, P. A Poisson/Nernst-Planck model for ionic transport through synthetic conical nanopores. Europhys. Lett. 71, 35-41 (2005).

68. Gillespie, D., Nonner, W. \& Eisenberg, R. S. Coupling Poisson-Nernst-Planck and density functional theory to calculate ion flux. J. Phys. Condens. Matter 14, 12129-12145 (2002).

69. Das, S. R., Majumder, S. B. \& Katiyar, R. S. Kinetic analysis of the $\mathrm{Li}^{+}$ion intercalation behavior of solution derived nano-crystalline lithium manganate thin films. J. Power Sources 139, 261-268 (2005).

70. Kalnaus, S., Sabau, A. S., Tenhaeff, W. E., Dudney, N. J. \& Daniel, C. Design of composite polymer electrolytes for $\mathrm{Li}$ ion batteries based on mechanical stability criteria. J. Power Sources 201, 280-287 (2012).

71. Zhang, X. et al. Rethinking how external pressure can suppress dendrites in lithium metal batteries. J. Electrochem. Soc. 166, A3639-A3652 (2019).

72. Bai, P. et al. Interactions between lithium growths and nanoporous ceramic separators. Joule 2, 2434-2449 (2018)

73. Choudhury, S. et al. Confining electrodeposition of metals in structured electrolytes. Proc. Natl Acad. Sci. USA 115, 6620 LP-6625 (2018).

74. Khoo, E., Zhao, H. \& Bazant, M. Z. Linear stability analysis of transient electrodeposition in charged porous media: Suppression of dendritic growth by surface conduction. J. Electrochem. Soc. 166, A2280-A2299 (2019).

75. Stalin, S., Choudhury, S., Zhang, K. \& Archer, L. A. Multifunctional crosslinked polymeric membranes for safe, high-performance lithium batteries. Chem. Mater. 30, 2058-2066 (2018).

76. Pan, R. et al. Sandwich-structured nano/micro fiber-based separators for lithium metal batteries. Nano Energy 55, 316-326 (2019).

77. Nakamura, K., Wada, M., Kuga, S. \& Okano, T. Poisson's ratio of cellulose I $\beta$ and cellulose II. J. Polym. Sci. Part B Polym. Phys. 42, 1206-1211 (2004).

78. Hao, F., Wang, W. \& Mukherjee, P. P. Mechano-electrochemical interaction in solid-state lithium batteries. J. Electrochem. Soc. 167, 80513 (2020).

79. Monroe, C. \& Newman, J. Dendrite growth in lithium/polymer systems a propagation model for liquid electrolytes under galvanostatic conditions. $J$. Electrochem. Soc. 150, A1377-A1384 (2003).

\section{Acknowledgements}

The central part of this work was supported by the NSF project "Energy- and CostEfficient Manufacturing Employing Nanoparticles" NSF 1463474 and Vannewar Bush DoD Fellowship to N.A.K. titled "Engineered Chiral Ceramics" ONR N000141812876. NSF 1566460 "Nanospiked Particles for Photocatalysis", NSF 1538180 is also gratefully acknowledged. Michigan Center for Materials Characterization (MC)2 is acknowledged for its assistance with electron microscopy, and for the NSF grant \#DMR-9871177 for funding of the JEOL $2010 \mathrm{~F}$ analytical electron microscope used in this work. M.W. acknowledges the support from China Postdoctoral Science Foundation (2020M681091), Heilongjiang Postdoctoral Fund (Grant No. LBH-Z19143). A.E.E. acknowledges scholarship for graduate studies from the Turkish Ministry of Education.

\section{Author contributions}

M.W. and A.E.E. performed the experiments and analyzed the data. J.Y.K., L.L., V.C., Y.T., and Y.H. conducted part of the analysis and characterizations. N.A.K. conceptualized the study, designed the experiments, and contributed to writing the paper. All authors discussed the results and commented on the manuscript.

\section{Competing interests}

The authors declare no competing interests.

\section{Additional information}

Supplementary information The online version contains supplementary material available at https://doi.org/10.1038/s41467-021-27861-w.

Correspondence and requests for materials should be addressed to Nicholas A. Kotov

Peer review information Nature Communications thanks the anonymous reviewers for their contribution to the peer review of this work.

Reprints and permission information is available at http://www.nature.com/reprints

Publisher's note Springer Nature remains neutral with regard to jurisdictional claims in published maps and institutional affiliations.

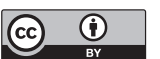

Open Access This article is licensed under a Creative Commons Attribution 4.0 International License, which permits use, sharing, adaptation, distribution and reproduction in any medium or format, as long as you give appropriate credit to the original author(s) and the source, provide a link to the Creative Commons license, and indicate if changes were made. The images or other third party material in this article are included in the article's Creative Commons license, unless indicated otherwise in a credit line to the material. If material is not included in the article's Creative Commons license and your intended use is not permitted by statutory regulation or exceeds the permitted use, you will need to obtain permission directly from the copyright holder. To view a copy of this license, visit http://creativecommons.org/ licenses/by/4.0\%

(C) The Author(s) 2022 